\title{
WestVirginiaUniversity
}

THE RESEARCH REPOSITORY @ WVU

Graduate Theses, Dissertations, and Problem Reports

2020

\section{Transit Agencies Performance Assessment and Implications}

\author{
Parisa Hajibabaee \\ West Virginia University, ph0031@mix.wvu.edu
}

Follow this and additional works at: https://researchrepository.wvu.edu/etd

Part of the Industrial Engineering Commons, Operational Research Commons, Other Operations

Research, Systems Engineering and Industrial Engineering Commons, and the Transportation Engineering

Commons

\section{Recommended Citation}

Hajibabaee, Parisa, "Transit Agencies Performance Assessment and Implications" (2020). Graduate Theses, Dissertations, and Problem Reports. 7700.

https://researchrepository.wvu.edu/etd/7700

This Thesis is protected by copyright and/or related rights. It has been brought to you by the The Research Repository @ WVU with permission from the rights-holder(s). You are free to use this Thesis in any way that is permitted by the copyright and related rights legislation that applies to your use. For other uses you must obtain permission from the rights-holder(s) directly, unless additional rights are indicated by a Creative Commons license in the record and/ or on the work itself. This Thesis has been accepted for inclusion in WVU Graduate Theses, Dissertations, and Problem Reports collection by an authorized administrator of The Research Repository @ WVU. For more information, please contact researchrepository@mail.wvu.edu. 
Transit Agencies Performance Assessment and Implications

\title{
Parisa Hajibabaee
}

Thesis submitted to the

Benjamin M. Statler College of Engineering and Mineral Resources at

West Virginia University

in partial fulfillment of the requirement for the degree of

Master of Science

in

Industrial Engineering

\author{
Dimitra Pyrialakou, Ph.D., Co-Chair \\ Leily Farrokhvar, Ph.D., Co-Chair \\ Kenneth Currie, Ph.D. \\ Behrooz Kamali, Ph.D.
}

Department of Industrial and Management Systems Engineering

Morgantown, West Virginia

July 2020

Keywords: Public Transit; Small Urban and Rural Areas; Data Envelopment Analysis; Ridehailing, Multi-Criteria Decision Analysis

Copyright: 2020 Parisa Hajibabaee 


\section{Abstract \\ Transit Agencies Performance Assessment and Implications}

\section{Parisa Hajibabaee}

Although most transit systems operate in small urban and rural areas in the United States, these systems have rarely received the same attention as their urban counterparts, both in terms of ensuring the efficiency and effectiveness of their operations and understanding the factors that affect their performance. This thesis's main goals are to assess the performance of rural and small urban public transit agencies and help them evaluate adopting a ridehailing program, thereby improving their performance. We applied operations research and decision-making tools to two public transit projects in small urban and rural areas. The first project focuses on three models developed to evaluate the efficiency, effectiveness, and combined efficiency-effectiveness of rural transit agencies using data envelopment analysis. The models were estimated for the case study of transit systems in rural Appalachia and measured the agencies' performance relative to their peers. Besides, the returns to scale were explored in the context of rural transit management. The second project focused on employing ridehailing programs in small urban and rural areas to improve agencies' performance and reach. The most relevant criteria were identified to evaluate the performance of different ridehailing programs using multi-criteria decision analysis methodology. To perform a set of MCDA methods, we used the perceived rating of each ridehailing program according to the stakeholders' opinions with respect to each criterion. The framework was estimated for the case study of Mountain Line Transit Authority in Morgantown, WV. 


\section{Acknowledgments}

First and foremost, I am sincerely grateful to my co-advisors, Dr. Dimitra Pyrialakou and Dr. Leily Farrokhvar, for their continuous support, patience, and timely suggestions for the completion of my research work. Thanks for being great advisors. I will always look up to both of you. I am also thankful to my committee members, Dr. Kenneth Currie and Dr. Behrooz Kamali, for their contribution and valuable feedback.

In addition, I would like to give special thanks to Dr. Majid Jaridi for his endless support and motivation during my time at West Virginia University.

Most importantly, I would like to express my deepest thanks to my lovely parents (Mansoureh and Hossein), my amazing siblings (Elham, Maryam, and Pedram), and my cute nieces (Nika, Glaris) for their unconditional love, unwavering support, and constant encouragement. Thanks for accepting me as I am, with my virtues and defects. I will always love you and never forget all the things you have done for me. 


\section{Table of Contents}

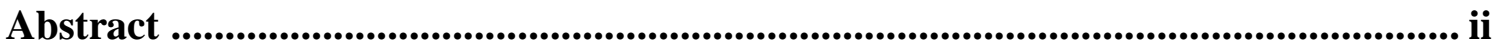

List of Tables ...................................................................................................... vi

List of Figures ............................................................................................... vi

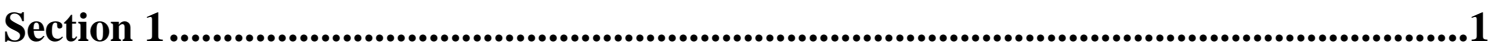

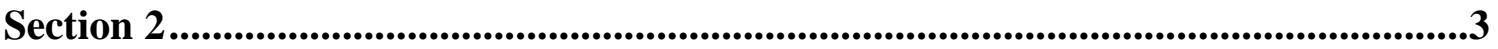

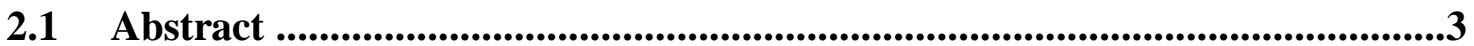

2.2 Introduction .................................................................................................3

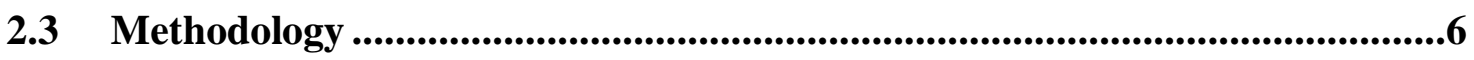

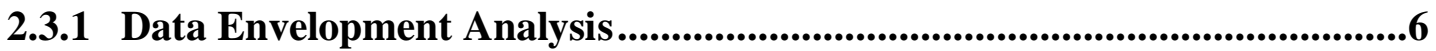

2.3.2 Selection of Variables......................................................................

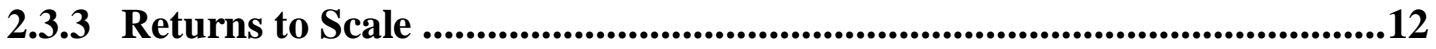

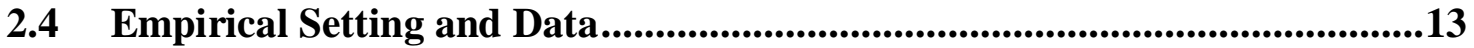

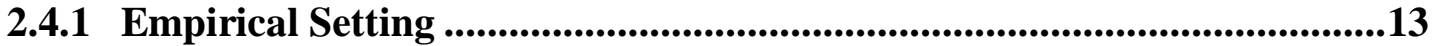

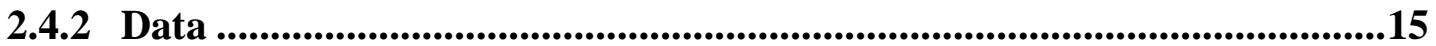

2.5 Case Study Results and Discussion ......................................................17

2.5.1 Efficiency, Effectiveness, and Combined Efficiency-Effectiveness Scores 17

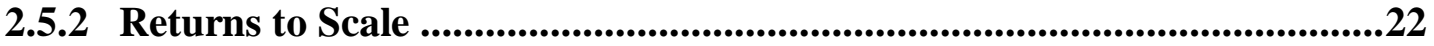

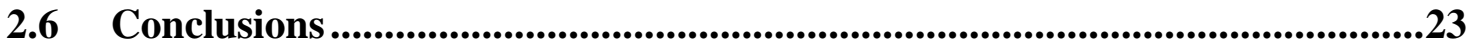

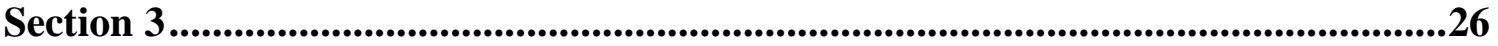

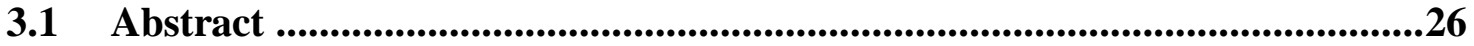

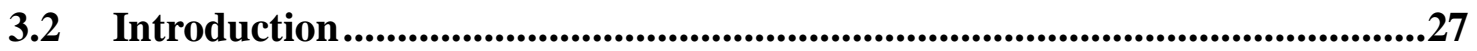

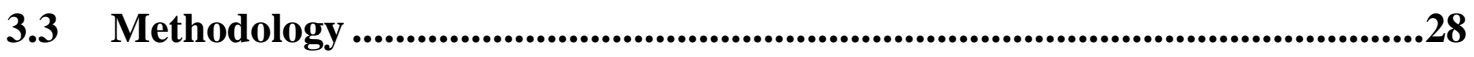

3.3.1 Multi-Criteria Decision Analysis ..............................................................29

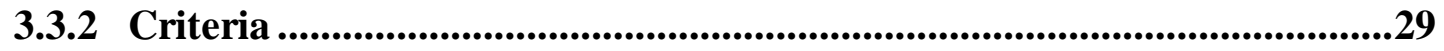


3.3.3 MCDA Methods .30

3.4 Application of the framework: A Case Study of Mountain line Transit Authority (MLTA) ....................................................................................................................37

3.4.1 Defining Criteria and Alternatives.....................................................................38

3.4.2 Data Collection ........................................................................................................41

3.5 Case Study Results and Discussion .........................................................................42

3.5.1 Weighted Criteria ...................................................................................................42

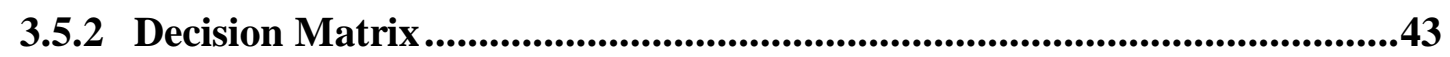

3.5.3 Equal Weights Assigned to Decision-Makers (DMs) ......................................45

3.5.4 Different Weights Assigned to Decision-Makers (DMs) ................................46

3.6 Conclusions .......................................................................................................................47

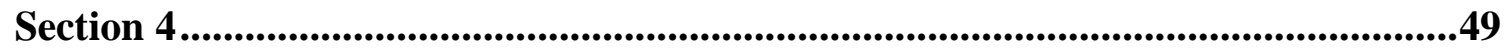

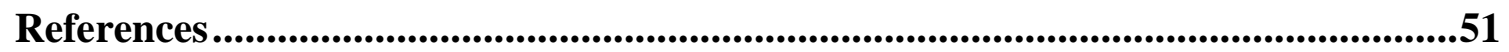




\section{List of Tables}

Table 1: Input-output Variables Used in the U.S Transit Literature .10

Table 2: State Descriptive Statistics for the Inputs and Outputs Used in the Analysis

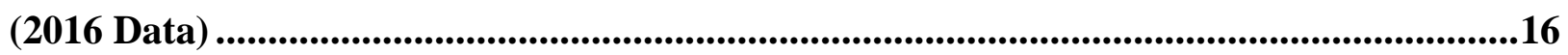

Table 3: Statistical Distribution of the Performance Scores..........................................18

Table 4: Average Performance Scores by State ................................................................19

Table 5: Correlation Statistics for Performance Ratings by State ..............................21

Table 6: Number and Share of Rural Transit Systems Operating Under Different

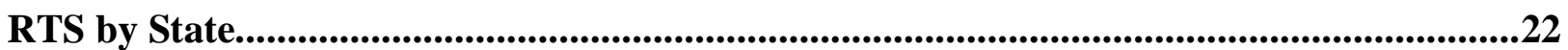

Table 7: The Comparisons of Four MCDM Methods in the Study ..............................37

Table 8: Criteria Suggested to Select the Best Ridehailing Programs.........................39

Table 9: Criteria Used to Select the Best Ridehailing Programs ..................................40

Table 10: Weighted Criteria .................................................................................................43

Table 11: Initial Decision Matrix for MCDA with All Criteria Considered as Benefit

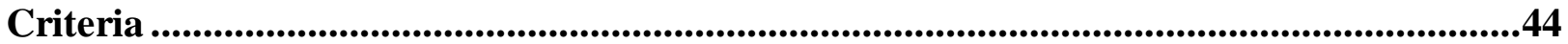

Table 12: Data Obtained by Ranking of the Alternatives Using Various MCDA

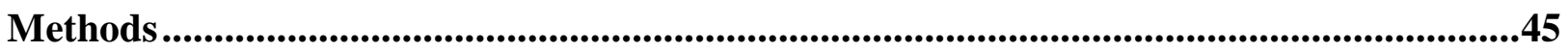

Table 13: Data Obtained by Ranking of the Alternatives Using Various MCDA Methods and Assigning Different Weights to DMs .46

\section{List of Figures}

Figure 1: The Appalachian region (designed using data from the United States department of agriculture (“USDA ERS - Rural-Urban Continuum Codes" n.d.)) ............14

Figure 2: Efficiency-Effectiveness scores of each state .19 


\section{Section 1 Thesis Overview}

In the United States, even though the majority of transit systems operate in small urban and rural areas (MacPherson and Dickens 2019), these systems have rarely received the same attention as their urban counterparts, both in terms of ensuring the efficiency and effectiveness of their operations and understanding the factors that affect their performance (Ripplinger 2012a). There are major differences in travel needs and available transport options between densely populated urban communities and rural/small urban areas based on community characteristics. Transit agencies in small urban and rural areas face significant operational challenges due to low ridership over a large expanse of land, traveling long distances, and first/last mile issues (Lockwood 2004). Given the decreasing budget and other operational restrictions, public transit providers have been exploring transportation solutions that can be employed, to meet people's travel needs, work in, or even visit their service area. Ridehailing services seems to be more cost beneficial than traditional fixed-route and demand-responsive services in smaller communities, which often remain unserved by transit. Nevertheless, agencies still have difficulties securing funds to utilize such services.

In this thesis, we apply operations research and decision-making tools to two public transit projects in small urban and rural areas. This thesis's main goals are to assess the performance of rural and small urban public transit agencies and help public transit evaluate adopting a ridehailing program, thereby improving their performance. One of the innovative approaches that public transit agencies in the U.S. have recently started exploring is partnerships with transportation network companies (TNCs) to improve performance and expand services. The practice is, however, neither widespread nor well studied, especially in small urban and rural areas. We present the proposed theoretical framework and findings from a case study in a small urban area that is currently considering developing a ridehailing program. The results will provide public transit authorities with insights that can guide strategic and operational planning.

The thesis objectives are to 
Develop a comprehensive performance evaluation framework that can be used to assess transit agencies' performance in rural areas considering key factors affecting the performance of transit agencies.

$>$ Explore the concept and applications of returns to scale, which is a key production characteristic, in the context of rural transit management.

$>$ Propose a framework to help transit agencies in rural and small urban communities to evaluate adopting a ridehailing program, and therefore, more easily achieve their goals and improve their effectiveness.

The remainder of the thesis is structured as follows: Section 2 presents three models developed to evaluate the efficiency, effectiveness, and combined efficiency-effectiveness of rural transit agencies using data envelopment analysis. The models are estimated for the case study of transit systems in rural Appalachia and measure the performance of the agencies relative to their peers. In addition, the concept of returns to scale is explored in the context of rural transit management. Section 3 focuses on the integration of public transit and ridehailing services in small urban and rural areas as a means to improve agencies' performance and reach. In this section, the most relevant criteria were identified to evaluate the performance of different ridehailing programs using multi-criteria decision analysis methodology. The framework was estimated for the case study of Mountain Line Transit Authority in Morgantown, WV. To perform a set of MCDA methods, we used the perceived rating of each ridehailing program according to the opinions of stakeholders with respect to each criterion. Section 4 summarizes the conclusions and discusses the implementation and limitations of the contribution. Finally, recommendations for future studies are provided in this section. 


\section{Section 2}

\section{Efficiency, Effectiveness, and Returns to Scale of Rural Transit Agencies Using Data Envelopment Analysis}

\subsection{Abstract}

This study proposes three models to evaluate the efficiency, effectiveness, and combined efficiency-effectiveness of rural transit agencies. For all three models, data envelopment analysis is applied to measure the performance of the agencies relative to their peers. In addition, the study explores the concept of returns to scale, a key production characteristic, in the context of rural transit management. The methodology is demonstrated through a case study of transit systems in rural Appalachia using 2016 data collected from the Rural Integrated National Transit Database (iNTD). The findings show that, in rural transit systems, efficiency and effectiveness are not always directly related, which suggests that performance must be evaluated holistically. Many large, efficient rural transit systems do not effectively serve passenger trips. Furthermore, the findings suggest that the optimal size of a rural transit agency depends on the agency's goals and mission; an absolute optimal size cannot be identified.

\subsection{Introduction}

Beginning in the 1970s, the research and practice of transit performance evaluation have received significant attention in the United States (U.S.) (Karlaftis 2003; 2004)). The U.S. government has been actively involved in providing public transit since 1961, when the first federal aid for transit was approved, and especially after 1974 when operating subsidies were added to the aid program (Wachs 1989). Since then, transit systems have relied heavily on federal, state, and local subsidies. In 2017, for example, transit agencies in the U.S. were able to recover only $36.7 \%$ of their operational expenses. The remaining $63.3 \%$ was covered by federal $(7.8 \%)$, state (23.1\%), and local (32.4\%) funding sources ("National Transit Summary and Trends" 2017). Therefore, it is not surprising that transit performance in the U.S. has been closely monitored since the 1970s. Transit performance is typically assessed with respect to efficiency and effectiveness. Generally, as (Fielding, Glauthier, and Lave 1978) discuss, efficiency is concerned with "doing things right", whereas effectiveness is concerned with "doing the right things". In the transit industry, efficient systems are those that utilize their limited service inputs well to produce service 
outputs (such as vehicle miles). On the other hand, effectiveness is associated with the outputs consumed or demanded (such as passenger miles).

Although the majority of transit systems in the U.S. operate in rural areas (MacPherson and Dickens 2019), rural transit systems have rarely received the same attention as their urban counterparts, both in terms of ensuring the efficiency and effectiveness of their operations and understanding the factors that affect their performance (Ripplinger 2012a). While rural transit has been financially supported since 1978, the Federal Transit Administration (FTA) only recently (2007 being the first reporting year) expanded the National Transit Database (NTD) program, which has maintained operating data for urban transit since the 1990s, to include rural transit agencies (i.e., those that receive funding from the Rural Formula Program [§5311]).

In addition to their shorter experience in data reporting and the paucity of literature focusing on rural transit performance, rural transit agencies often generate a lower percentage of their operational costs and are generally less effective (based on standard performance measures of effectiveness, such as cost per passenger trip) than urban transit agencies. Many factors contribute to this disparity, such as uneven topography, populations scattered across large regions, and a low density of both population and destinations, all of which result both in longer distance trips and lower ridership. Irrespective of the reasons, the fare recovery ratio is typically smaller for rural and small urban bus transit systems than for urban bus transit systems, while their operational expenses are comparatively higher per trip. According to data reported in the NTD and the rural Integrated National Transit Database (iNTD), in 2015, most (1st to 3rd quartile) urban agencies spent, per passenger trip, between $\$ 4.16$ and \$5.90, small urban agencies spent between $\$ 4.79$ and $\$ 9.15$, and rural agencies spent between $\$ 9.25$ and $\$ 21.72$ ("National Transit Summary and Trends" 2017; Mattson 2017).

The evaluation methods proposed by the numerous studies on urban transit performance evaluation can be grouped into two categories: methods using performance measures and peer evaluation methods. The latter, which compare performance across agencies to identify successful operations strategies, has been sought by both transit and funding agencies because they can provide useful insights on transit system performance (Arndt and Edrington 2011). Such methodologies can be especially informative for rural transit, where individual performance measures can be misleading due to the significant diversity among different rural areas. Peer 
systems' performance can be empirically estimated using one of two types of methods: parametric or non-parametric. In parametric methods, a functional form is specified, and the relevant techniques can be deterministic or stochastic. In non-parametric methods, no functional form is assumed, and usually a deterministic frontier is established.

Among the methods used for peer comparison, data envelopment analysis (DEA), a nonparametric method, has become well-established for its usefulness in assessing the performance of transit; a vast body of literature has been generated in the U.S. (e.g., (Karlaftis 2003; 2004; Chu, Fielding, and Lamar 1992; James F. Nolan 1996; Viton 1997; Nakanishi and Norsworthy 2000; Boilé 2001; J. F. Nolan, Ritchie, and Rowcroft 2002; James Francis Nolan, Ritchie, and Rowcroft 2001; Lao and Liu 2009; Min and Lambert 2010; Barnum, Karlaftis, and Tandon 2011; Arman, Labi, and Sinha 2012; Arman and Labi 2013; Min, Ahn, and Lambert 2015)) and internationally (e.g.,(Hahn et al. 2013; Vlahogianni, Kepaptsoglou, and Karlaftis 2015)). Nevertheless, this methodology has yet to be applied to rural areas. In addition to evaluating the performance of rural transit agencies, this methodology can be expanded to measure the returns to scale (RTS) of rural transit agencies. RTS can be directly used to inform transit planning and guide funding allocation decisions because they capture a key production characteristic: the relationship between the cost of operations and the level of output produced by transit agencies or consumed by riders.

In light of the above, the objective of this study is to use DEA to develop a peer evaluation method capable of assessing the performance of rural transit agencies and determining their RTS and apply this method to the case of systems in the U.S. Appalachian region. The method involves (Karlaftis 2003)using three sets of models to evaluate the comparative efficiency, effectiveness, and combined efficiency-effectiveness, respectively, of rural transit systems among their peers (i.e., all rural transit systems within the Appalachian region); (Karlaftis 2004)exploring the relationships among the three different components of performance (i.e., efficiency, effectiveness, and combined efficiency-effectiveness) for all rural transit systems within each state in the Appalachian region; and (Wachs 1989) analyzing the type of RTS for all rural transit agencies in the region.

As various studies have recognized, the results of performance analysis and the determination of returns to scale are valuable and can be used for both internal and external 
purposes (Karlaftis 2004). Results for individual transit agencies can be used by the agencies to evaluate their operations and implement best practices. In addition, these results can inform state and regional transit planning and guide funding decisions at the federal and state levels. Furthermore, in this study we explore results aggregated at the state level, which facilitates a comparison across states in the Appalachian region and can provide insights at a higher level.

The remainder of the study is organized as follows. The second subsection presents the research approach proposed in this study, including the methods, data, and inputs and outputs selected to estimate the performance models. The third subsection discusses the empirical setting and the data used in the case study. The fourth subsection presents the results of the analysis, and the final section outlines the conclusions and future works and discusses the planning and policy implications of this work.

\subsection{Methodology}

\subsubsection{Data Envelopment Analysis}

DEA is a non-parametric multiple input-output efficiency technique that can measure the relative efficiency of transit systems using a linear programming-based model. It is nonparametric because it requires no assumptions regarding the shape or parameters of the underlying production function. Because of this feature, the popularity of DEA has increased in the last three decades. (Chames, Cooper, and Rhodes 1978) proposed the original model (i.e., the Charnes, Cooper, and Rhodes [CCR] model) assuming constant returns to scale (CRS) for the underlying production technology. Later, (Banker, Charnes, and Cooper 1984)extended the model (i.e., the Banker, Charnes, and Cooper [BCC] model) to include variable returns to scale (VRS) (for details on these methods, refer to (Cooper, Seiford, and Tone 2007)). The basic idea behind the DEA model is the estimation of a "virtual" input consisting of the weighted inputs of a system or decision-making unit (DMU), which is considered to be the agency responsible for the production of a "virtual" output consisting of the weighted outputs. Then, using linear programming, the weights are determined so as to maximize the ratio of "virtual" output to input (Cooper, Seiford, and Tone 2007), which can be done either by minimizing the input for a given amount of output (input orientation) or by maximizing the output for a given amount of input (output orientation). For more information on the origins and details of this methodology, the reader should refer to 
(Hartman, Kurtz, and Winn 1994; "National Transit Database (NTD) Glossary” 2015; Min and Lambert 2010).

In this study, three sets of input-oriented models are designed that consider both CRS and VRS. As discussed by (Viton 1997), who followed an input orientation, we explore the possibility that systems can reduce their inputs to achieve the same amount of output without compromising performance. Input orientation, as well as both CRS and VRS, have been frequently used in transit studies based on DEA (refer to Table 1, p. 1481, of (Hahn et al. 2013)).

The input-oriented optimization problem under CRS, in an envelopment form, is written as:

$\operatorname{Min} \theta$

Subject to $Y \lambda-y_{i} \geq 0$,

$\theta x_{i}-X \lambda \geq 0$

$\lambda \geq 0$.

Where $\theta$ is a scalar and $\lambda$ is a $N \times 1$ vector of constants, $y_{i}$ is the vector of M outputs $(m=1 \ldots$ $M)$, and $x_{i}$ is the vector of $\mathrm{K}$ inputs $(k=1, \ldots, K)$ of the $i=1, \ldots, N$ DMU, while $(X, Y)$ is the input and output matrix. The above equation is adapted from (Cooper, Seiford, and Tone 2007). In this study, each DMU represents a specific transit system in the year of analysis. The value of $\theta$ is estimated for every DMU and corresponds to its performance score. In other words, the above problem attempts to locate a "virtual" DMU among the pool of DMUs considered that corresponds to a perfectly efficient DMU (i.e., a DMU on the frontier). The constraints dictate that this virtual DMU should produce at least as much output, and with at least as much input, as $\mathrm{DMU}_{\mathrm{i}}$. Solving the problem stated above, it can be shown that the DEA yields $\theta$ scores between 0 and 1 , with 1 denoting that the DMU is efficient, or, in other words, that it is located on the frontier. Then, considering VRS, the assumption of CRS is relaxed with the addition of the restriction $N 1^{\prime} \lambda=1$ (where $N 1$ is an all-one $N \times 1$ vector).

\subsubsection{Selection of Variables}

As (Fielding, Glauthier, and Lave 1978) discussed, different aspects of transit performance can be evaluated under two different sets of goals: efficiency and effectiveness. In addition, combined performance measures can be designed in such a way as to combine the main aspects 
of both sets of criteria. A transit system can be considered efficient when it performs well in producing transit services, specifically in utilizing the available inputs to reach the expected output. A transit system can be considered effective when it performs well in a comparison between the services actually provided and those intended. As described in a 2009 Transit Cooperative Research Program (TCRP) report (Ellis and McCollom 2009) and earlier reports by the Federal Transit Administration (such as (Hartman, Kurtz, and Winn 1994)), transit practice in the U.S. associates efficiency with the output "produced" (e.g., vehicle revenue miles) and effectiveness with the output "consumed" (e.g., passenger trips) (Ripplinger 2012b).

As for the inputs of the systems, three different components have been mainly used in the literature: labor, fuel, and capital. Other external factors that might affect the systems' performance have also been considered.

Table 1 presents the main input and output variables used in the U.S. transit literature. It should be noted that labor and capital are represented by the number of employees and vehicles, respectively, of transit systems, while fuel consumed is quantified in terms of gallons. Furthermore, based on ("National Transit Database (NTD) Glossary" 2015), unlinked passenger trips (UPT) are defined as "the number of passengers who board public transit vehicles. Passengers are counted each time they board vehicles, no matter how many vehicles they use to travel from their origin to their destination." Meanwhile, ridership is defined as "the number of rides taken by people using a public transit system in a given period." Because the NTD and iNTD databases do not include annual linked passenger trip data, in Table 1 these terms are used interchangeably.

In view of the above, this study proposes three different sets of models to evaluate the efficiency, effectiveness, and combined efficiency-effectiveness, respectively, of rural transit systems. The last model is suggested to diminish the intended error in the measurement process and improve the reliability and validity of the measures. Based on the variables used in the literature (shown in Table 1) and considering both the availability of data and the unique characteristics of rural transit as outlined in TCRP report 136 (Ellis and McCollom 2009), in all three models two input variables are used: (1) Total Operating Expenses and (2) Total Revenue Vehicles in Total Fleet. In terms of the outputs, the efficiency model utilizes Annual Vehicle Revenue Miles, and the effectiveness model utilizes Total Unlinked Passenger Trips. A combined 
efficiency-effectiveness model is also proposed that combines both output variables (Annual Vehicle Revenue Miles and Total Unlinked Passenger Trips) using equal weights. All of the variables above are among the key variables used to evaluate the performance of rural transit agencies according to the TCRP guidelines (Ellis and McCollom 2009). Note that we use total vehicle revenue miles instead of total vehicle miles because including deadhead miles could penalize systems that operate within county or town limits in comparison to those that operate across counties. 
Table 1: Input-output Variables Used in the U.S Transit Literature

\begin{tabular}{|c|c|c|c|c|c|c|c|c|c|c|}
\hline \multirow[b]{2}{*}{ Model } & \multicolumn{6}{|c|}{ Input (In terms of) } & \multicolumn{4}{|c|}{ Output (In terms of) } \\
\hline & Study & Labor & Capital & Fuel & Expenses & Other & $\begin{array}{r}\text { Vehicle } \\
\text { Miles }\end{array}$ & $\begin{array}{r}\text { Vehicle } \\
\text { Hours }\end{array}$ & $\begin{array}{c}\text { Ridership } \\
\text { (UPT) }\end{array}$ & Other \\
\hline \multirow{9}{*}{ Efficiency } & (Karlaftis 2004) & $\checkmark$ & $\checkmark$ & $\checkmark$ & & & $\checkmark$ & & & \\
\hline & (Chu, Fielding, and Lamar 1992) & & & & $\begin{array}{l}\text { VOEXP, } \\
\text { MEXP, } \\
\text { GAEXP }\end{array}$ & & & $\checkmark$ & & \\
\hline & (James F. Nolan 1996) & $\checkmark$ & $\checkmark$ & $\checkmark$ & & & $\checkmark$ & & & \\
\hline & $\begin{array}{l}\text { (J. F. Nolan, Ritchie, and } \\
\text { Rowcroft 2002) }\end{array}$ & $\checkmark$ & $\checkmark$ & $\checkmark$ & & & $\checkmark$ & & & \\
\hline & $\begin{array}{c}\text { (James Francis Nolan, } \\
\text { Ritchie, and Rowcroft 2001) }\end{array}$ & $\checkmark$ & $\checkmark$ & $\checkmark$ & & $\begin{array}{l}\text { Network } \\
\text { length }\end{array}$ & $\checkmark$ & & & \\
\hline & (Min and Lambert 2010) & & $\checkmark$ & & OEXP & PM & $\checkmark$ & $\checkmark$ & & $\begin{array}{c}\text { Fare } \\
\text { revenues }\end{array}$ \\
\hline & $\begin{array}{l}\text { (Barnum, Karlaftis, and } \\
\text { Tandon 2011) }\end{array}$ & & & & OEXP & & & $\checkmark$ & & \\
\hline & $\begin{array}{c}\text { (Karlaftis and Tsamboulas } \\
\text { 2012) }\end{array}$ & $\checkmark$ & $\checkmark$ & $\checkmark$ & & & $\checkmark$ & & & \\
\hline & $\begin{array}{l}\text { (Georgiadis, Politis, and } \\
\text { Papaioannou 2014) }\end{array}$ & & $\checkmark$ & & & $\begin{array}{c}\text { Line length, } \\
\text { Span of } \\
\text { service }\end{array}$ & & $\checkmark$ & & \\
\hline \multirow{5}{*}{ Effectiveness } & (Karlaftis 2004) & $\checkmark$ & $\checkmark$ & $\checkmark$ & & & & & $\checkmark$ & \\
\hline & $\begin{array}{l}\text { (Chu, Fielding, and Lamar } \\
\text { 1992) }\end{array}$ & & & & & $\begin{array}{l}\text { RVH, } \\
\text { UZADEN, } \\
\text { PNOVEH, } \\
\text { ASIPAS }\end{array}$ & & & $\checkmark$ & \\
\hline & (Lao and Liu 2009) & & & & & $\begin{array}{c}\text { Span of } \\
\text { service, Line } \\
\text { length, } \\
\text { Number of } \\
\text { stops } \\
\end{array}$ & & & $\checkmark$ & \\
\hline & $\begin{array}{l}\text { (Georgiadis, Politis, and } \\
\text { Papaioannou 2014) }\end{array}$ & & $\checkmark$ & & & $\begin{array}{l}\text { Length, Span } \\
\text { of service }\end{array}$ & & & $\checkmark$ & \\
\hline & $\begin{array}{c}\text { (Sampaio, Neto, and Sampaio } \\
\text { 2008) }\end{array}$ & $\checkmark$ & $\checkmark$ & & OEXP & & & & $\checkmark$ & \\
\hline
\end{tabular}




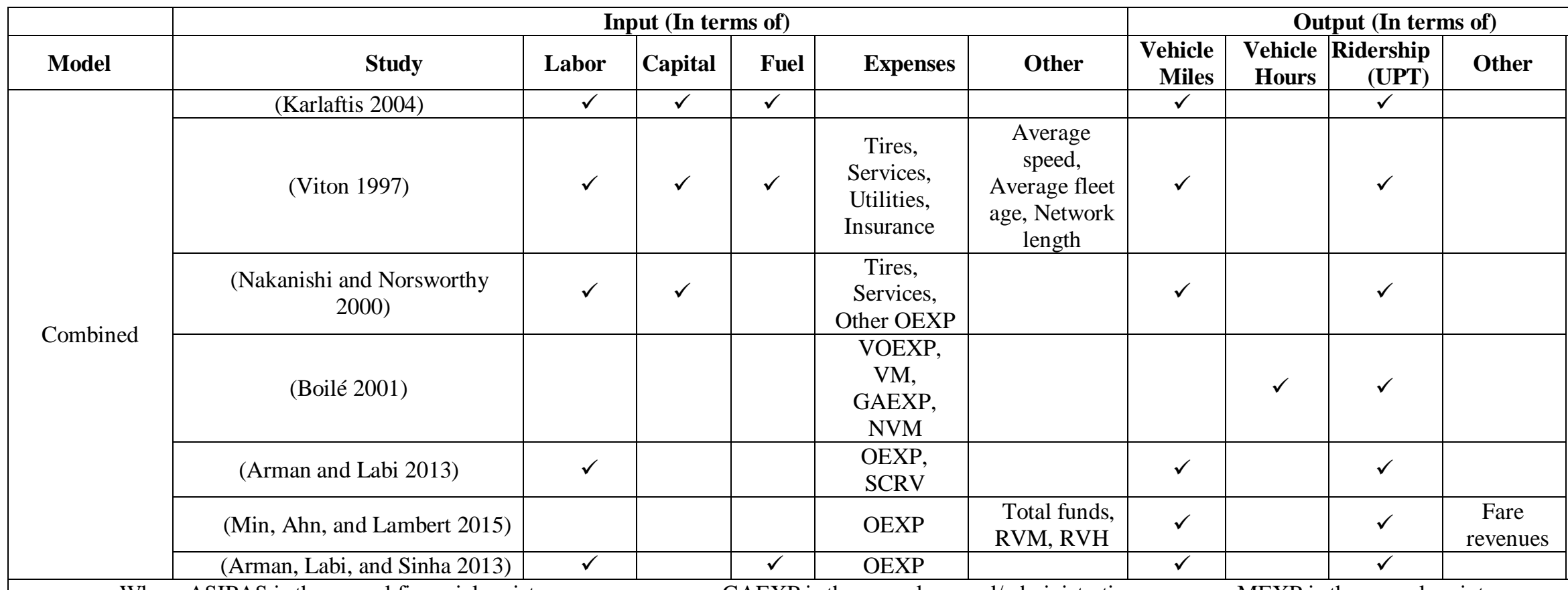

Where ASIPAS is the annual financial assistance per passenger, GAEXP is the annual general/administrative expenses, MEXP is the annual maintenance expenses, NVM is the annual nonvehicle maintenance expenses, OEXP is the operating expenses, PM is the passenger miles, PNOVEH is the proportion of households without automobiles, RVH is the revenue vehicle hours, RVM is the revenue vehicle miles, SCRV is the total seat capacity of revenue vehicle fleet, TRAS is the annual unlinked passenger trips, UZADEN is the urbanized area population density, VM is the annual vehicle maintenance expenses, VOEXP is the annual vehicle operating expenses. 
It should be clarified that all articles reviewed in Table 1 are categorized into the following three models: efficiency, effectiveness, and combined efficiency-effectiveness. This classification is based on the definitions of the models of efficiency, effectiveness, and combined efficiencyeffectiveness adopted in this study, regardless of the original model name and classification in the cited paper. Here, the output variables play a substantial role, such that the efficiency model utilizes vehicle miles or hours as an output while the effectiveness model utilizes ridership, and the combined model utilizes a combination of both output variables.

\subsubsection{Returns to Scale}

This section discusses the determination of RTS based on the BCC method. According to (Jahanshahloo, Soleimani-Damaneh, and Rostamy-Malkhalifeh 2005), it can be supposed that we have $n$ DMUs, where each DMUj, $\mathrm{j}=1,2, \ldots, \mathrm{n}$ produces the same s outputs using the available

inputs $\mathrm{m}$. The amount of outputs yrj, $(\mathrm{r}=1,2, \ldots, \mathrm{s})$ and amount of inputs $x_{i j}(\mathrm{i}=1,2, \ldots, \mathrm{m})$ can vary among DMUj. The efficiency of a specific DMUo can be evaluated using the input-oriented BCC model for DEA, which is presented in its multiplier form as follows, adopted from (Lin and Zhang 2010):

$\operatorname{Max} \quad z=\sum_{r=1}^{s} u_{r} y_{r 0}-u_{0}$

Subject to $\sum_{r=1}^{s} u_{r} y_{r 0}-u_{0}-\sum_{i=1}^{m} v_{i} x_{i j}-u_{0} \leq 0, \forall j$

$$
\begin{aligned}
& \sum_{i=1}^{m} v_{i} x_{i 0}=1, \\
& v_{i} \geq 0, u_{r} \geq 0 .
\end{aligned}
$$

In Eq. (5), the optimal values of this variable can be used to identify the RTS.

Following the above equations, the efficiency can be defined as follows: A DMU is efficient if and only if both (1) and (2) hold:

(1) The optimal value of Eq. (5) is equal to 1.

(2) There exists one optimal solution with $v_{i} \geq 0, u_{r} \geq 0$.

Then, we can determine the RTS according to the following RTS theorem(Lin and Zhang 2010; Banker and Thrall 1992). 
Let $(X O, Y O)$ be efficient. The following conditions identify the situation for RTS for a given model:

I. Constant RTS prevail at $(\mathrm{X} 0, \mathrm{Y} 0)$ if and only if $\mathrm{u}^{*} 0=0$ for at least one optimal solution.

II. Increasing RTS prevail at (X0, Y0) if and only if $\mathrm{u}^{*} 0<0$ for all optimal solutions.

III. Decreasing RTS prevail at $(\mathrm{X} 0, \mathrm{Y} 0)$ if and only if $\mathrm{u}^{*} 0>0$ for all optimal solutions.

Where $\mathrm{Xo}=(\mathrm{X} 10, \mathrm{X} 20 \ldots \mathrm{Xm} 0)$ and $\mathrm{Y} 0=(\mathrm{Y} 10, \mathrm{Y} 20 \ldots \mathrm{Ys} 0)$ are the input-output vectors of DMU0.

There are three possible types of RTS: increasing returns to scale (IRS), constant returns to scale (CRS), and decreasing returns to scale (DRS). If output increases by the same proportional change as all inputs, then CRS prevails. If output increases by less than the proportional change of all inputs, then DRS prevails. If output increases by more than the proportional change of all inputs, then IRS prevails. A firm's production function might exhibit different types of returns to scale at different ranges of output. A DMU operating under IRS is more productive because its percentage increase in output is proportionally greater than the percentage increase in the use of all inputs. Consequently, as output increases a decline in the long-run average unit costs is anticipated.

\subsection{Empirical Setting and Data}

\subsubsection{Empirical Setting}

This section presents the empirical setting of rural Appalachia, which is used as a case study to illustrate the proposed methodology. The Appalachian region covers 205,000 square miles and includes all of West Virginia and portions of 12 other states from New York to Mississippi, as Figure 1 shows. The 420 counties of the region are grouped into five subregions based on similarities in economic and demographic characteristics and geographic location (Northern Appalachia, North Central Appalachia, Central Appalachia, South Central Appalachia, and Southern Appalachia). While Appalachia is a distinct part of the U.S., the region is far from homogeneous, including both rural counties and major metropolitan areas such as Pittsburgh, Birmingham, and parts of suburban Atlanta ("USDA ERS - Urban Influence Codes” 2019). 
Figure 1 depicts the rural and urban county types in the Appalachian region.

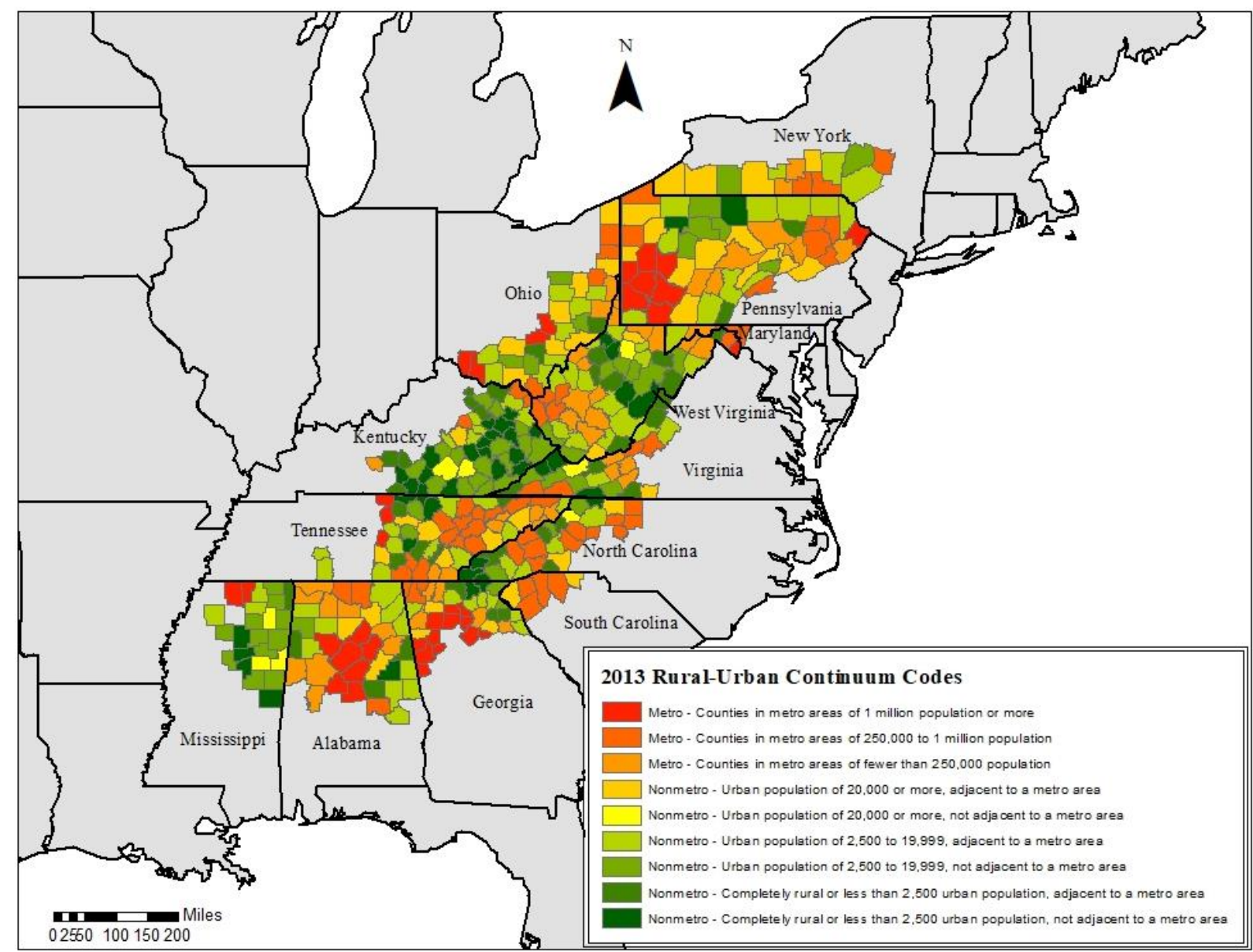

Figure 1: The Appalachian region (designed using data from the United States department of agriculture ("USDA ERS - Rural-Urban Continuum Codes" n.d.))

Rural Appalachia encompasses about 47,363 square miles of land and a population of approximately 2,501,699. According to a data overview of the Appalachian region (Pollard and Jacobsen 2018), rural and nonmetro areas in Appalachia have seen a marked decrease in population since 2010 compared to an increase in the U.S. Furthermore, the region includes a notably higher elderly population than the U.S. average. In 2017 , more than $18.5 \%$ of the population in rural and nonmetro areas in Appalachia was 65 years old or older, much higher than the national average of $15.6 \%$. Rural Appalachia also has a higher unemployment rate compared to the national average and a higher percentage of people living in poverty. Furthermore, the percentage of people with disabilities is higher than average. Nevertheless, the people of rural and 
nonmetro Appalachia are more dependent on personal automobiles. While the share of commuters using transit is approximately 5\% in the U.S., the share in the entire Appalachian region is 1\%, and the share in rural and nonmetro Appalachia is as low as $0.3 \%$. For the population living below the poverty line, this percentage is slightly higher, but is still much lower than the national averages for this group. These statistics emphasize the need to improve and expand transit services in rural and nonmetro Appalachia.

\subsubsection{Data}

The case study utilizes annual data from 2016 to illustrate the proposed methodology. The data was submitted to the rural iNTD by rural transit agencies receiving FTA funding from the Rural Formula Program (\$5311). Within the 13 states of the Appalachian Region, in 2016, 94 agencies provided rural transit services in 2016, as reported by the rural iNTD. Data from 2016 was the most recent available on the iNTD website at the time of analysis. Of the 94 rural transit agencies in Appalachia, 10 were excluded from our data set because their 2016 data lacked certain data points from several variables needed for analysis. Five additional agencies lacked data points for only one input variable (Total Revenue Vehicles in Total Fleet). Statistical methods were used in an attempt to replace these missing data points with reasonable values. However, because DEA is a data-oriented and non-parametric method and the models used in this study included only two input variables, the value of each variable significantly affects the results of the DEA. Therefore, it was determined that the missing data could be reasonably replaced for one of the five agencies using a trend technique because sufficient data was available from previous years. The other four agencies were excluded from the data set. With these 14 agencies removed, the data set used for the models includes 80 rural transit agencies within 12 states in Appalachia; the number of states has decreased because both agencies located in South Carolina were excluded.

Table 2 presents the descriptive statistics of the main variables utilized in the analysis by state. 
Table 2: State Descriptive Statistics for the Inputs and Outputs Used in the Analysis (2016 Data)

\begin{tabular}{|c|c|c|c|c|c|c|}
\hline State & $\begin{array}{c}\text { No of } \\
\text { Agencies }\end{array}$ & Statistics & $\begin{array}{c}\text { Total } \\
\text { Operating } \\
\text { Expense }\end{array}$ & $\begin{array}{c}\text { Total } \\
\text { Revenue } \\
\text { Vehicles in } \\
\text { Total Fleet }\end{array}$ & $\begin{array}{c}\text { Total Unlinked } \\
\text { Passenger } \\
\text { Trips }\end{array}$ & $\begin{array}{c}\text { Annual Vehicle } \\
\text { Revenue Miles }\end{array}$ \\
\hline \multirow{2}{*}{ Alabama } & \multirow{2}{*}{3} & Mean & 201,589 & 8 & 9,810 & 74,576 \\
\hline & & St. Dev. & 32,014 & 2 & 3,590 & 26,609 \\
\hline \multirow{2}{*}{ Georgia } & \multirow{2}{*}{17} & Mean & 169,056 & 3 & 14,604 & 82,131 \\
\hline & & St. Dev. & 70,472 & 1 & 9,227 & 32,928 \\
\hline \multirow{2}{*}{ Kentucky } & \multirow{2}{*}{8} & Mean & $3,240,070$ & 69 & 286,109 & $1,841,681$ \\
\hline & & St. Dev. & $3,262,701$ & 65 & 370,988 & $2,190,011$ \\
\hline \multirow{2}{*}{ Maryland } & \multirow{2}{*}{1} & Mean & $1,205,025$ & 20 & 111,233 & 734,286 \\
\hline & & St. Dev. & $0 *$ & $0 *$ & $0 *$ & $0^{*}$ \\
\hline \multirow{2}{*}{ Mississippi } & \multirow{2}{*}{4} & Mean & 975,649 & 27 & 124,292 & 523,769 \\
\hline & & St. Dev. & 416,244 & 8 & 76,650 & 235,229 \\
\hline \multirow{2}{*}{ New York } & \multirow{2}{*}{4} & Mean & $1,153,582$ & 18 & 90,378 & 308,614 \\
\hline & & St. Dev. & 460,047 & 5 & 57,387 & 115,243 \\
\hline \multirow{2}{*}{ North Carolina } & \multirow{2}{*}{14} & Mean & 812,336 & 17 & 52,800 & 388,388 \\
\hline & & St. Dev. & 966,214 & 13 & 45,035 & 408,718 \\
\hline \multirow{2}{*}{ Ohio } & \multirow{2}{*}{8} & Mean & 927,807 & 16 & 57,189 & 317,359 \\
\hline & & St. Dev. & 704,830 & 6 & 53,179 & 208,883 \\
\hline \multirow{2}{*}{ Pennsylvania } & \multirow{2}{*}{2} & Mean & $2,719,404$ & 38 & 204,288 & $1,120,488$ \\
\hline & & St. Dev. & $1,431,185$ & 19 & 70,209 & 787,215 \\
\hline \multirow{2}{*}{ Tennessee } & \multirow{2}{*}{4} & Mean & $5,002,905$ & 130 & 238,760 & $2,740,852$ \\
\hline & & St. Dev. & $1,221,413$ & 53 & 76,178 & 346,030 \\
\hline \multirow{2}{*}{ Virginia } & \multirow{2}{*}{5} & Mean & $1,194,678$ & 33 & 115,003 & 515,212 \\
\hline & & St. Dev. & 621,717 & 21 & 44,777 & 292,674 \\
\hline \multirow{2}{*}{ West Virginia } & \multirow{2}{*}{10} & Mean & 924,781 & 23 & 89,547 & 396,354 \\
\hline & & St. Dev. & 504,721 & 7 & 74,547 & 207,449 \\
\hline
\end{tabular}

* The standard deviation is 0 because there is only one agency in the state. 
Table 2 shows that the characteristics of each state vary significantly, as captured in the highly varying standard deviations and the numbers of rural transit agencies in each state. The table above shows that Tennessee, Kentucky, and Pennsylvania exhibit the highest means and standard deviations for all input and output variables, whereas Alabama and Georgia exhibit the lowest values. Interestingly, Kentucky and North Carolina, with 8 and 14 rural transit agencies, respectively, include extremely diverse transit agencies in terms of their input variables. This finding is captured in the standard deviations shown in Table 2, which were sometimes found to be higher than the mean values.

\subsection{Case Study Results and Discussion}

\subsubsection{Efficiency, Effectiveness, and Combined Efficiency-Effectiveness Scores}

In this chapter, three sets of input-oriented models are designed considering both CRS and VRS. The values resulting from the models differ between the VRS and CRS approaches. Although the results of the CRS DEA are simple and easier to interpret, the values yielded by the VRS DEA are more accurate. Additionally, the extended model (BCC) can be used to determine RTS, as explained in the methodology section. Therefore, in this section, only the results of the VRS DEA are reported. Detailed results for every rural transit agency included in this study, estimated using both the CRS and VRS approaches are available at the following URL: https://tinyurl.com/yxzhjyjf.

Table 3 shows the statistical distribution of the performance scores of three models using 2016 data. 
Table 3: Statistical Distribution of the Performance Scores

\begin{tabular}{|c|c|c|c|}
\hline Range of Scores & Efficiency & Effectiveness & Combined \\
\hline$[0.00-0.10)$ & 0 & 0 & $\mathbf{0}$ \\
\hline$[0.10-0.20)$ & 0 & 1 & 0 \\
\hline$[0.20-0.30)$ & 0 & 12 & 0 \\
\hline$[0.30-0.40)$ & 8 & 18 & 2 \\
\hline$[0.40-0.50)$ & 10 & 13 & 9 \\
\hline$[0.50-0.60)$ & 11 & 9 & 11 \\
\hline$[0.60-0.70)$ & 17 & 8 & 12 \\
\hline$[0.70-0.80)$ & 13 & 4 & 14 \\
\hline$[0.80-0.90)$ & 6 & 2 & 12 \\
\hline$[0.90-1.00)$ & 3 & 1 & 3 \\
\hline $1.00^{*}$ & 12 & 12 & 17 \\
\hline Total number of Transit Systems & 80 & 80 & 80 \\
\hline Mean Score & 0.67 & 0.53 & 0.74 \\
\hline Median & 0.68 & 0.47 & 0.75 \\
\hline St. Dev. & 0.20 & 0.26 & 0.19 \\
\hline Minimum & 0.32 & 0.19 & 0.38 \\
\hline Maximum & 1 & 1 & 1 \\
\hline
\end{tabular}

*A DEA score equal to 1 indicates a DMU located on the frontier

(or a perfectly efficient and/or effective transit system)

The Table suggests that approximately $15 \%$ of the transit systems are perfectly efficient and perfectly effective (12 out of the 80 systems) and that $21 \%$ have a perfect combined efficiency-effectiveness relative to their peers (17 out of the 80 systems). In addition, the table shows that, although the distributions of efficiency and combined efficiency-effectiveness are leftskewed, the distribution of effectiveness is right-skewed. This finding indicates that, overall, transit systems in the Appalachian region are more efficient than they are effective.

Table 4 shows the average BCC scores for different models by state. Figure 2 depicts the same average efficiency and effectiveness scores by state to facilitate a comparison. 
Table 4: Average Performance Scores by State

\begin{tabular}{|c|c|c|c|c|}
\cline { 3 - 5 } \multicolumn{2}{c|}{} & Efficiency & Effectiveness & Combined \\
\hline State & $\begin{array}{c}\text { No of } \\
\text { Agencies }\end{array}$ & Avg. Score (St. Dev.) & Avg. Score (St. Dev.) & Avg. Score (St. Dev.) \\
\hline Georgia & 3 & $0.48(0.07)$ & $0.42(0.10)$ & $0.47(0.03)$ \\
\hline Kentucky & 17 & $0.85(0.16)$ & $0.79(0.20)$ & $0.75(0.14)$ \\
\hline Maryland & 8 & $0.74(0.18)$ & $0.51(0.27)$ & $0.75(0.16)$ \\
\hline Mississippi & 4 & $1.00\left(0^{*}\right)$ & $1.00\left(0^{*}\right)$ & $1.00\left(0^{*}\right)$ \\
\hline New York & 4 & $0.60(0.17)$ & $0.55(0.22)$ & $0.73(0.21)$ \\
\hline North Carolina & 14 & $0.49(0.10)$ & $0.51(0.31)$ & $0.60(0.25)$ \\
\hline Ohio & 8 & $0.66(0.15)$ & $0.39(0.09)$ & $0.68(0.13)$ \\
\hline Pennsylvania & 2 & $0.55(0.17)$ & $0.38(0.19)$ & $0.61(0.17)$ \\
\hline Tennessee & 4 & $0.74(0.26)$ & $0.62(0.04)$ & $0.76(0.17)$ \\
\hline Virginia & 5 & $0.77(0.08)$ & $0.28(0.06)$ & $0.72(0.08)$ \\
\hline West Virginia & 10 & $0.61(0.19)$ & $0.63(0.31)$ & $0.75(0.21)$ \\
\hline
\end{tabular}

* The standard deviation is 0 because there is only one agency in the state.

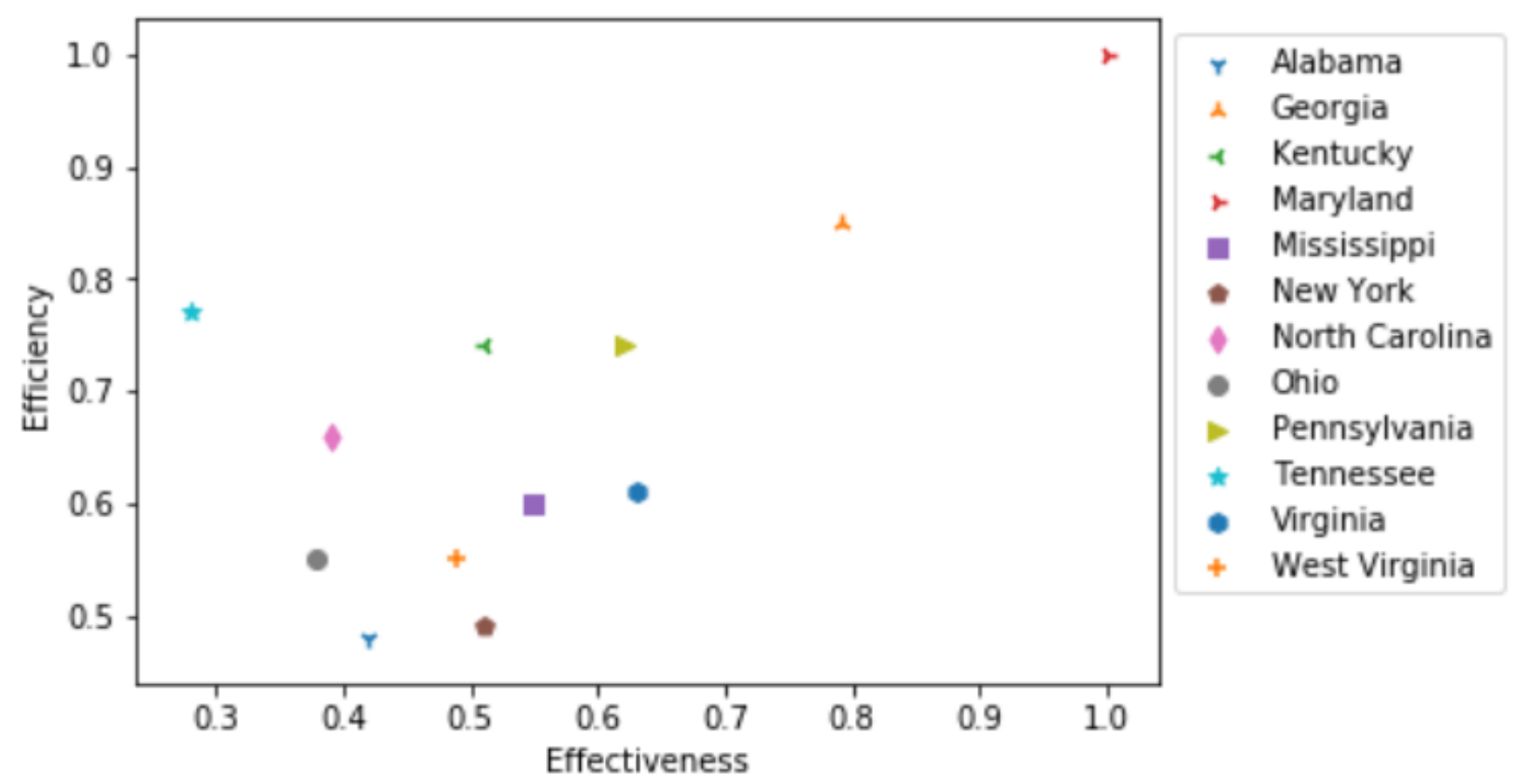

Figure 2: Efficiency-Effectiveness scores of each state 
As the table and figure show, transit systems in Georgia, Tennessee, and Kentucky perform better on average in terms of efficiency, while transit systems in Georgia, Virginia, and Pennsylvania perform better on average in terms of effectiveness. However, it seems that transit systems in Pennsylvania, Georgia, Kentucky, and Virginia perform better on average in terms of combined efficiency-effectiveness. The findings also show that, generally, the 17 transit systems in Georgia appear to be performing well, in that the state has among the highest average scores and relatively small standard deviations for all three models. Georgia's systems are also among the smallest systems on average in terms of vehicles, ridership, and vehicle revenue miles, as Table 2 shows. Furthermore, the performance of Tennessee's 4 transit systems seems to be similar across those 4 systems, with the systems having high efficiency but relatively low effectiveness scores. From Table 2, it can be inferred that Tennessee's transit systems are relatively larger than other states' systems. Kentucky's 8 transit systems are also relatively large and also seem to be more efficient than they are effective, but there is more variation across the 8 agencies (as captured in the standard deviation of the scores). In contrast, the transit systems of Virginia are, on average, effective, but they are only somewhat efficient (their average is approximately the same as the average of the whole data set). However, it seems that, like in Kentucky, the systems that operate in Virginia are diverse in terms of their performance (evident in the high standard deviations). Finally, as Table 3 shows, Maryland has just one rural transit agency, which is in the frontier for all three models, and Pennsylvania has just two, which are quite different from each other in terms of both size (as Table 2 shows) and performance (as Table 3 shows). Finally, as Figure 2 shows, Maryland and Georgia can be considered the only states in which transit systems operate both efficiently and effectively, while in the rest of the states, the agencies perform on average better in one of the two aspects of performance.

Table 5 presents the relationships among the efficiency, effectiveness, and combined efficiency-effectiveness ratings for each state. For all systems, if the rating of one performance attribute is positively related to the ratings of the other two attributes, this simply implies that, for a number of operational and administrative reasons, efficient systems also tend to be effective systems. 
Table 5: Correlation Statistics for Performance Ratings by State

\begin{tabular}{|c|c|c|c|c|c|c|c|}
\hline & Effic. & Effect. & Comb. & & Effic. & Effect. & Comb. \\
\hline Alabama & & & & $\begin{array}{l}\text { North } \\
\text { Carolina }\end{array}$ & & & \\
\hline Efficiency & 1 & & & Efficiency & 1 & & \\
\hline Effectiveness & -0.74 & & & Effectiveness & 0.01 & 1 & \\
\hline Combined & 0.98 & 0.6 & & Combined & 0.96 & 0.27 & 1 \\
\hline Georgia & & & & Ohio & & & \\
\hline Efficiency & 1 & & & Efficiency & 1 & & \\
\hline Effectiveness & 0.89 & & & Effectiveness & -0.29 & 1 & \\
\hline Combined & 0.98 & 91 & & Combined & 0.7 & 0.45 & 1 \\
\hline Kentucky & & & & Pennsylvania & & & \\
\hline Efficiency & 1 & & & Efficiency & 1 & & \\
\hline Effectiveness & 0.3 & & & Effectiveness & 1 & 1 & \\
\hline Combined & 0.88 & 56 & & Combined & 1 & 1 & 1 \\
\hline Maryland & & & & Tennessee & & & \\
\hline Efficiency & \multirow{3}{*}{\multicolumn{3}{|c|}{$\begin{array}{l}\text { Excluded from the } \\
\text { analysis } \\
\text { (only one data point } \\
\text { was available) }\end{array}$}} & Efficiency & 1 & & \\
\hline Effectiveness & & & & Effectiveness & -0.05 & 1 & \\
\hline Combined & & & & Combined & 0.93 & 0.22 & 1 \\
\hline Mississippi & & & & Virginia & & & \\
\hline Efficiency & 1 & & & Efficiency & 1 & & \\
\hline Effectiveness & 0.7 & & & Effectiveness & 0.69 & 1 & \\
\hline Combined & 0.96 & 85 & & Combined & 0.87 & 0.91 & 1 \\
\hline New York & & & & West Virginia & & & \\
\hline Efficiency & 1 & & & Efficiency & 1 & & \\
\hline Effectiveness & 0.55 & & & Effectiveness & 0.34 & 1 & \\
\hline Combined & 0.72 & .97 & & Combined & 0.8 & 0.81 & 1 \\
\hline
\end{tabular}


Interestingly, the results in Table 5 indicate that efficiency is positively related to combined efficiency-effectiveness in almost every state, but not necessarily effectiveness. This finding is somewhat unexpected because it contradicts previous findings in the literature of urban transit (see for example (Karlaftis 2004)). In the case of Alabama, it can even be inferred that efficiency and effectiveness are highly negatively correlated, while Ohio and Tennessee exhibit a slight inverse relationship between efficiency and effectiveness ( -0.29 and -0.05 , respectively). We also note that the results of all three models for Pennsylvania are strongly correlated, but there are only two rural transit systems in the Appalachian region of the state included in the analysis. It should also be noted that Maryland has been excluded from the analysis, as the results would not be meaningful because the Appalachian portion of the state has just one rural transit agency included in the analysis.

\subsubsection{Returns to Scale}

Table 6 presents the number and percentage of agencies operating under different RTS types in 2016 , as reported by all three models.

Table 6: Number and Share of Rural Transit Systems Operating Under Different RTS by State

\begin{tabular}{|c|c|c|c|c|c|c|c|c|c|c|}
\hline \multirow[b]{3}{*}{ State } & \multicolumn{9}{|c|}{ Returns to Scale } & \multirow[b]{3}{*}{ Total } \\
\hline & \multicolumn{3}{|c|}{ Efficiency Based } & \multicolumn{3}{|c|}{ Effectiveness Based } & \multicolumn{3}{|c|}{ Combined Based } & \\
\hline & CRS & DRS & IRS & CRS & DRS & IRS & CRS & DRS & IRS & \\
\hline \multirow{2}{*}{ Alabama } & & & 3 & & & 3 & & & 3 & \\
\hline & & & $(\mathbf{1 0 0 \% )}$ & & & $(\mathbf{1 0 0 \% )}$ & & & $(\mathbf{1 0 0 \% )}$ & 3 \\
\hline \multirow{2}{*}{ Georgia } & & 1 & 16 & & & 17 & & & 17 & \\
\hline & & $(6 \%)$ & $(94 \%)$ & & & $(\mathbf{1 0 0 \% )}$ & & & $(\mathbf{1 0 0 \% )}$ & 17 \\
\hline \multirow{2}{*}{ Kentucky } & 4 & 3 & 1 & & 4 & 4 & 1 & 5 & 2 & \\
\hline & $(50 \%)$ & $(38 \%)$ & $(12 \%)$ & & $(50 \%)$ & $(50 \%)$ & $(12 \%)$ & $(63 \%)$ & $(25 \%)$ & 8 \\
\hline \multirow{2}{*}{ Maryland } & & 1 & & & & 1 & & 1 & & \\
\hline & & $(100 \%)$ & & & & $(\mathbf{1 0 0 \% )}$ & & $(\mathbf{1 0 0 \%})$ & & 1 \\
\hline \multirow{2}{*}{ Mississippi } & 2 & & 2 & & 2 & 2 & & 2 & 2 & \\
\hline & $(50 \%)$ & & $(50 \%)$ & & $(50 \%)$ & $(50 \%)$ & & $(50 \%)$ & $(50 \%)$ & 4 \\
\hline \multirow{2}{*}{ New York } & 1 & 2 & 1 & & 1 & 3 & 1 & 2 & 1 & \\
\hline & $(25 \%)$ & $(50 \%)$ & $(25 \%)$ & & $(25 \%)$ & $(75 \%)$ & $(25 \%)$ & $(50 \%)$ & $(25 \%)$ & 4 \\
\hline \multirow{2}{*}{ North Carolina } & 6 & 1 & 7 & & 1 & 13 & 4 & 1 & 9 & \\
\hline & $(43 \%)$ & $(7 \%)$ & $(50 \%)$ & & $(7 \%)$ & $(93 \%)$ & $(28 \%)$ & $(7 \%)$ & $(64 \%)$ & 14 \\
\hline \multirow{2}{*}{ Ohio } & 3 & 1 & 4 & & 1 & 7 & 1 & 1 & 6 & \\
\hline & $(38 \%)$ & $(12 \%)$ & $(50 \%)$ & & $(12 \%)$ & $(\mathbf{8 8 \%})$ & $(12 \%)$ & $(12 \%)$ & $(75 \%)$ & 8 \\
\hline \multirow{2}{*}{ Pennsylvania } & & 2 & & & 2 & & & 2 & & \\
\hline & & $(100 \%)$ & & & $(100 \%)$ & & & $(100 \%)$ & & 2 \\
\hline \multirow{2}{*}{ Tennessee } & & 4 & & & 4 & & & 4 & & \\
\hline & & $(100 \%)$ & & & $(100 \%)$ & & & $(100 \%)$ & & 4 \\
\hline \multirow{2}{*}{ Virginia } & 5 & & & & 2 & 3 & 1 & 2 & 2 & \\
\hline & $(100 \%)$ & & & & $(40 \%)$ & $(60 \%)$ & $(20 \%)$ & $(40 \%)$ & $(40 \%)$ & 5 \\
\hline \multirow{2}{*}{ West Virginia } & 3 & 1 & 6 & & 2 & 8 & 4 & 2 & 4 & \\
\hline & $(30 \%)$ & $(10 \%)$ & $(60 \%)$ & & $(20 \%)$ & $(80 \%)$ & $(40 \%)$ & $(20 \%)$ & $(40 \%)$ & 10 \\
\hline Total (\#) & 24 & 16 & 40 & $\mathbf{0}$ & 19 & 61 & 12 & 22 & 46 & \multirow{2}{*}{80} \\
\hline Total $(\%)$ & $(30 \%)$ & $(20 \%)$ & $(50 \%)$ & $(0 \%)$ & $(24 \%)$ & $(76 \%)$ & $(15 \%)$ & $(27 \%)$ & $(58 \%)$ & \\
\hline
\end{tabular}


Interestingly, the efficiency-based RTS results show that exactly one-half of the rural transit systems appear to be operating under IRS. In addition, the effectiveness-based RTS results show that no system is operating under CRS and that nearly $76 \%$ of systems are operating under IRS. The findings are consistent with the literature, in that the results appear to be affected by the output specification, and thus different systems seem to operate under different RTS types when the estimations are based on efficiency, effectiveness, or combined efficiency-effectiveness (see (Karlaftis 2004)).

The findings suggest that most transit systems in Georgia operate under IRS based on both efficiency and effectiveness. In contrast, Tennessee's transit systems operate under DRS based on both efficiency and effectiveness. Most of Kentucky's systems seem to operate under either CRS or DRS based on efficiency or combined efficiency-effectiveness, and half of the agencies seem to operate under IRS based on effectiveness. Both systems in Pennsylvania operate under DRS and all three systems in Alabama operate under IRS, no matter the output specification. In North Carolina, although most systems are not highly effective (as shown by the low average effectiveness scores in Table 4), all but one of the systems appear to operate under IRS based on effectiveness. The systems in the remaining states operate under a mix of increasing, constant, and decreasing returns to scale, depending on the output specification.

\subsection{Conclusions}

Significant amounts of research have been undertaken to develop methods for evaluating transit system performance because the efficacy of public sector service providers in terms of the optimal use of resources is considered critical. In this study, a DEA methodology to assess the efficiency, effectiveness, and combined efficiency and effectiveness of rural transit systems was proposed. We used a medium-sized data set that included operational data for 80 transit systems in the Appalachian region for the year 2016. In addition to evaluating the agencies' performance, we explored the returns to scale of the agencies in the region.

Because DEA is a non-parametric multiple input-output efficiency technique, the selection of inputs and outputs can significantly affect the results. A wide variety of parameters have been considered in the literature, but to the authors' knowledge no study has provided a comprehensive overview of these input-output parameters. This study reviewed and summarized all key parameters that have been considered in the U.S. transit literature and selected the most suitable 
variables for rural transit evaluation in light of data availability, the unique characteristics of rural transit, and the TCRP guidelines' (Ellis and McCollom 2009) recommendations.

The findings of the performance analysis have many implications. In terms of evaluating the performance of rural transit systems, the efficiency and effectiveness of these systems are not necessarily related. In addition, the findings suggest that combined efficiency-effective seems to be more strongly affected by the output produced (e.g., vehicle miles) than the output consumed (e.g., passenger trips). These findings emphasize the need, in practice, to evaluate rural transit systems in a holistic way and in more than one dimension.

In terms of regional planning, the findings show that, overall, rural agencies in the Appalachian region are more efficient than they are effective. In fact, many of the systems seem to be much less effective than they can be (relative to their peers). This finding is somewhat anticipated because effectiveness is highly dependent on the output consumed. In other words, attracting ridership is one of the key challenges for many rural transit systems in the U.S., whether due to the low populations and population densities of the areas served, the low density of destinations, high automobile dependence, or other area-specific reasons. Furthermore, many of the larger systems seem to be relatively efficient but not effective (especially true for systems operating in Tennessee and Kentucky). This finding suggests that to perform well, an agency does not necessarily have to be large in terms of passengers served, distance covered, vehicles in operation, etc. This conclusion is corroborated by the finding that Georgia's transit systems, which are relatively small, seem to be the most efficient and effective agencies.

For the RTS analysis, the findings of this work corroborated previous literature on urban transit and demonstrated that the type of RTS that an agency operates under depends on the output specification. This finding implies that there is no single optimal size for a rural transit agency where the optimum RTS is achieved. Instead, the optimal size depends on the aspect of performance the agency wants to enhance. Because, as we previously discussed, increasing a rural transit system's efficiency does not necessarily increase its effectiveness, this implication is especially important for the practice of rural transit agencies. To guide funding and planning decisions, states and local funding agencies should encourage rural transit agencies to develop well-planned operational strategies based on the agencies' goals and missions. 
In terms of regional planning, the findings suggest that, depending on the output specification, half or more of the agencies perform under IRS. Rural agencies experiencing IRS are expected to have decreasing long-run average costs as their operations expand. Based on these observations, it is expected that an increase in ridership should, in many cases, both decrease the average unit costs and increase the effectiveness of rural transit systems in the region. Ineffective systems could explore strategies that can help increase ridership (such as targeted marketing or travel training), and states could facilitate this exploration by providing guidance and targeted funding. A future case study of Georgia's systems can perhaps provide insights and best practices for the Appalachian region.

Even using a limited dataset, the findings suggest that the DEA methodology is a strong and insightful peer evaluation method that can be used to explore the performance of rural transit systems. It should be noted that even though the case study in this study focused on rural Appalachia, the proposed methodology is easily transferable to any rural area in the U.S. because of the standardized data collection required by the FTA and the reporting practices of the iNTD. An investigation of external factors that might affect transit performance, such as population density and other socioeconomic and demographic characteristics, distance of the subject region from an urban center, or the accessibility of services, might also provide valuable insights. Such an investigation could be conducted using DEA methodologies (e.g., second-stage DEA) or standard econometric techniques. Furthermore, while this study used data from a single year, it would be possible to perform an analysis using panel data. However, although the iNTD provides data as far back as 2007 , for many agencies the data sets for certain years are incomplete, and therefore researchers would have to either work with a relatively small set of agencies for which complete data are available or use data imputation methods that might affect the results of the analysis. 


\section{Section 3}

\section{Evaluation of Ridehailing Programs as an Additional Service of Transit Agencies in Small Urban Areas Using Multi-Criteria Decision Analysis}

\subsection{Abstract}

One of the innovative approaches that public transit agencies in the U.S. have recently started exploring is partnership with transportation network companies (TNCs) to improve performance and expand services. However, the practice is neither widespread nor well-studied, especially in small urban and rural areas. Although practitioners have begun exploring the potential economic impacts of transit-ridehailing partnerships, literature has yet to provide a comprehensive methodology that assesses and prioritizes the ridehailing programs before starting the partnership.

In this research, we present both the theoretical framework proposed and findings from a case study of MLTA that is currently considering to develop a ridehailing program. We identified the most relevant criteria from literature to evaluate the performance of different ridehailing programs using multi-criteria decision analysis methodology. Perceived rating of each ridehailing program, with respect to each criterion, has been used in accordance with the opinions of the stakeholders to employ a set of MCDA methods. This case study and the framework used can help agencies to evaluate adopting a ridehailing program, and therefore, more easily achieve their goals and improve their effectiveness. The findings of this study show that the perceived optimal ridehailing program, resulting from a partnership between MLTA and a TNC, is substituting lowfrequency fixed-route services with on-demand service for the general public in areas previously serviced by the fixed route. 


\subsection{Introduction}

Traditionally, public transit services have been categorized as Fixed-Route Transit (FRT), which tends to be more cost-effective, and Demand-Responsive Transit (DRT) (Garrett 2014). With technology improvements, a new class of private mobility service providers named Transportation Network Companies (TNCs) have emerged over the past decade to exploit mobile technology and digital networks to link customers with mobility options. Recently, it can be seen that some public transit providers have started to partner with some TNCs like Uber and Lyft to either improve or even substitute their existing service in terms of employing ridehail programs within their transit systems.

Conceptually, ridehailing refers to a system in which travelers hire a personal driver by smartphone apps to book and pay. Riders could be picked up and dropped off exactly where they want and usually without several stops along a route or sharing with other riders. Transit agencies considering partnering with a TNC may be interested in specific ridehailing programs to achieve specific goals such as mobility improvements, cost savings, increased access to transit, or improved customer satisfaction

Given the decreasing funding and other increasing operational restrictions, public transit providers have been exploring transportation solutions that can be employed to meet the travel needs of people who live in, work in or even visit their service area. Although partnering with a TNC in rural and small urban areas is currently rare, transit agencies have started partnering with TNCs like Uber and Lyft to either expand or substitute existing service in urban areas. For example, Pinellas Suncoast Transit Authority (PSTA), provider for Pinellas County in Florida has developed TNC partnerships in response to service cuts owing to low ridership. Instead of cutting service to some areas entirely, Pinellas Suncoast Transit began discounting Uber rides \$5 (Schwieterman and Livingston 2019). Boston can also be considered a good example of a densely populated urban community which has cooperated with Lyft and Uber to provide conventional paratransit service, resulting in considerable cost savings over handling the operation in-agency (Schwieterman and Livingston 2019).

On the other hand, there are several transit agencies in rural and small urban areas that are eager to work on short- to medium-term transit plans to investigate required changes, enhancements, and expand their current level of service to improve their efficiency and 
effectiveness. Performance and service improvements and service expansions are expected to satisfy current public transit users and attract more riders to the systems. There are several motivations and reasons which have resulted in the selection of ridehailing programs that vary according to the target customers and main purpose of ridehailing programs such as first mile/last mile connection, late night transportation, or on demand services. Although practitioners have begun exploring the potential benefits of a partnership with TNCs, literature has yet to provide a methodology that assesses and quantifies these benefits of employing a ridehailing program within a public transit environment.

In this study, we suggest four ridehailing programs for a public transit agency in a small urban area. We also identify a set of criteria from the literature to help agencies evaluate adopting a ridehailing program, and therefore, more easily achieve their goals and improve their effectiveness. To assess the performance of suggested ridehailing programs, a comparative analysis of different kinds of MCDA methods to show the similarity and differences of methods was used. The proposed methods can be used to prioritize a ridehailing program option for the current public transit system before starting the partnership between public transit and a TNC. We illustrate the proposed method using a case study approach. We explore several cases of transitridesharing partnerships, specifically the case of PSTA, which we met with regarding their three different ridehailing programs, and the case of Mountain Line Transit Authority (MLTA), operating in Monongalia County, WV, which is currently considering to develop a ridehailing program. We asked stakeholders of MLTA to rate the alternatives with respect to each criterion. Then by assigning different weights to stakeholders, we compared the result of the ranking of alternatives.

\subsection{Methodology}

The majority of decision problems in the public sector have a multiple criteria character with many possible alternatives and many uncertainties as well as many stakeholders with various interests (Walker 2000). Therefore, a variety of measures and dimensions must be considered to analyze such complex decision problems. Most of the time, policymakers use different tools to help them come to a decision concerning the consequences of policy and to rank alternative solutions. In this study, multi-criteria decision analysis (MCDA), a range of methods for evaluating a number of alternatives according to various, frequently contradictory decision criteria 
(Triantaphyllou 2000), is used to prioritize ridehailing program options for the case study of Mountain Line Transit Authority (MLTA).

\subsubsection{Multi-Criteria Decision Analysis}

The application of multi-criteria decision analysis (MCDA) in the transit industry has been widely used within a broad scope, ranging from a specific program's performance assessment to strategic planning and infrastructural projects (Żak, Hadas, and Rossi 2017). MCDA is a wellknown methodology aiming to enable decision-makers to solve multi-criteria decision problems by providing different computational methods and computer-based tools to consider complex trade-offs among alternatives (Żak, Hadas, and Rossi 2017). The main objective of MCDA methodology is to help policymakers select the preferable choice from several possible alternatives, taking into account a wide range of criteria. It also allows the integration of quantitative and qualitative information/input into a single assessment/output (Lami 2014). In this section, the definition of criteria and some of the well-known MCDA methods are briefly discussed.

\subsubsection{Criteria}

The factors that are used to evaluate the alternatives are called criteria. The criteria can be determined through discussion meetings with decision-makers by considering the decision objectives. Then the attributes of criteria should be identified. There are different ways to measure an attribute, depending on the decision-makers' goal. When defining each criterion, the main question should be: how would you like to measure success/progress towards the goal? Criteria can be categorized as beneficial, i.e., the higher value, the better result, and non-beneficial, i.e., the lower value leads to a better result (Seed 2017).

\subsubsection{Weighting of Criteria}

The weights of each criterion reveal the importance of the various evaluation criteria. Relative importance is generally represented through some form of quantitative importance "weight." Stakeholders or decision-makers assign a relative weight to every criterion, based on the perceived importance of the criterion. It is necessary to involve a group of unbiased decisionmakers in such a weighting process (Hassan, Hawas, and Ahmed 2013). This will ensure fairness 
and reflect unbiased judgments. In the following, we present the general formulation of criteria weighting that we used in this study.

Let $j$ denote the criterion index $C_{j}, j=1, \ldots, n$. A group of E experts are asked to rate each criterion, $R_{j e}$, where e is the index of the expert, $e=1, \ldots, E$.

The rates allocated by each expert $e$ to each criterion $j$, are averaged $R_{j}^{I}$ (as shown in Eq. (9)) to estimate the rate of each criterion $j$. Each expert rates each criterion using a scale as an example of 1 to 5 (1: not at all important to 5: extremely important). Then the weight for each criterion $j, W_{j}$, will be calculated as shown in Eq. (10) while the weights should be nonnegative values that sum to 1 based on Eq. (11).

$$
\begin{aligned}
& R_{j}^{I}=\frac{\sum_{e=1}^{E}\left(R_{j e}\right)}{E}, \quad \forall j, j=1,2, \ldots, n \\
& W_{j}=\frac{R_{j}^{I}}{\sum_{j=1}^{n} R_{j}^{I}}, \quad \forall j, j=1,2, \ldots, n \\
& \sum_{j=1}^{n}\left(W_{j}\right)=1 .
\end{aligned}
$$

\subsubsection{MCDA Methods}

An array of MCDA methods, each with their own characteristics, varying levels of complexity and varied scope of application can be found in the literature (Mulliner, Malys, and Maliene 2016). The goal of MCDA methods is to provide ranking of each alternative, given a set of relevant decision criteria and alternatives. In the following, we discuss four different MCDA methods namely, WSM, TOPSIS, PROMETHEE, and VIKOR that we used in this study. According to (Broniewicz and Ogrodnik 2020), methods such as TOPSIS, PROMETHEE II, and VIKOR were identified as some the most common methods used for the selected decision problems in transit industry.

\subsubsection{WSM- Weighted Sum Method}

The weighted sum method (WSM) is probably the most commonly used approach for evaluating some alternatives, given some decision criteria (Triantaphyllou 2000). The additive utility assumption introduced in (Fishburn 1967) is the basis of this model.

The weighted sum method (WSM) has the following steps: 
Step 1: Construct the decision matrix and determine the weight of criteria

Step 2: Calculate the sum of weighted decision matrix for each alternative

In cases where all the criteria are valued in the same unit (e.g., dollars, minute), the WSM method can be utilized easily. However, when applied to a data set with various units, the normalization step would be added to the WSM process steps. By data normalization, the units of measurement for data will be eliminated enabling us to compare data from different sources more easily.

If there are $m$ alternatives and $n$ decision criteria, then the total value of each alternative is equal to Eq. (12)(Fishburn 1967):

$$
A_{i}^{W S M-s c o r e}=\sum_{j=1}^{n} w_{j} a_{i j}, \quad \text { for } i=1, \ldots, m
$$

Where $w_{j}$ denotes the relative weight of importance of $j^{\text {th }}$ criterion and $a_{i j}$ is the performance value of the $i^{\text {th }}$ alternative in terms of $j^{\text {th }}$ criterion.

When the criteria are estimated in different units, a normalization step is required. In this

case, $r_{i j}$ is normalized performance value of the $i^{\text {th }}$ alternative in terms of $j^{\text {th }}$ criterion and should be replaced of $a_{i j}$ in Eq. (12). Beneficial criteria can be normalized as Eq. (13)(Vafaei, Ribeiro, and Camarinha-Matos 2018):

$$
r_{i j}=\frac{a_{i j}}{a_{j}^{m a x}}
$$

Furthermore, non-beneficial criteria are computed as Eq. (14) (Vafaei, Ribeiro, and Camarinha-Matos 2018):

$$
r_{i j}=1-\frac{a_{i j}}{a_{j}^{\text {max }}}
$$

Step 3: Rank the alternatives, sorting by the values $A_{i}^{W S M-s c o r e}$, in decreasing order.

The best alternative is the one that achieves the highest total performance value.

\subsubsection{TOPSIS-Technique for the Order of Preference by Similarity to the Ideal Solution}

The Technique for Order of Preference by Similarity to Ideal Solution (TOPSIS) is a multicriteria decision analysis method that was developed in 1981 by Ching-Lai Hwang and Yoon 
(Hwang and Yoon 1981). TOPSIS is a practical method for ranking and selecting several possible alternatives by measuring Euclidean distances. The fundamental concept of TOPSIS method is that the preferred alternative should have the shortest distance from the ideal-best solution and the farthest from the ideal-worst solution (Hwang and Yoon 1981; Yoon 1980). Also, according to the carried out review of world literature, TOPSIS is one of the most well-known MCDA methods in transit application area for evaluating a number of feasible solutions/alternatives against a number of criteria (Broniewicz and Ogrodnik 2020).

The steps to apply the TOPSIS method for $m$ alternatives and $n$ criteria can be described as the following (The equations are based on (Opricovic and Tzeng 2004)):

Step 1: Construct the decision matrix and determine the weight of criteria

Step 2: Calculate the normalized decision matrix

in TOPSIS, the vector normalization is utilized (Opricovic 1998), as Eq. (15) (Vafaei, Ribeiro, and Camarinha-Matos 2018).

$$
r_{i j}=\frac{a_{i j}}{\sqrt{\sum_{k=1}^{m} a_{k j}^{2}}}, i=1,2, \ldots, m, j=1,2, . ., n
$$

Step 3: Calculate the weighted normalized decision matrix as Eq. (16).

$$
t_{i j}=r_{i j} \cdot w_{j}
$$

Step 4: Determine the positive ideal and negative ideal solutions

$v_{+}=t_{j}^{\max }$, for $j \epsilon$ beneficial criteria

$v_{+}=t_{j}^{\min }$, for $j \epsilon$ non-beneficial criteria

$v_{-}=t_{j}^{\text {min }}$, for $j \epsilon$ beneficial criteria

$v_{-}=t_{j}^{\max }$, for $j \epsilon$ non-beneficial criteria

Step 5: Calculate Euclidean distance from the ideal best and ideal worst value

$$
s_{i}^{+}=\sqrt{\sum_{j=1}^{n}\left(t_{i j}-v_{+}\right)^{2}}, \forall j=1.2 \ldots, n
$$




$$
s_{i}^{-}=\sqrt{\sum_{j=1}^{n}\left(t_{i j}-v_{-}\right)^{2}}, \forall j=1.2 \ldots, n
$$

Step 6: Calculate performance score

$$
p_{i}=\frac{s_{i}^{-}}{s_{i}^{-}+s_{i}^{+}}
$$

Step 7: Rank the preference order or select the alternative closest to 1

\subsubsection{PROMETHEE II: Preference Ranking Organization Method for Enrichment Evaluation}

PROMETHEE II is one of the most widely used outranking methods. Its basic concept is based on a pair-wise comparison of alternatives along with each criterion recognized. Logistics and Transportation is one of the earliest topics in the literature of PROMETHEE methods. (Behzadian et al. 2010).

The compromise ranking algorithm PROMETHEE II has the following steps, equations are based on (Behzadian et al. 2010):

Step 1: Construct the decision matrix and determine the weight of criteria

Step 2: Normalize the Evaluation Matrix (Decision Matrix) using Minimum-Maximum method as shown below:

$$
\begin{aligned}
& r_{i j}=\frac{a_{i j}-\min \left(a_{i j}\right)}{\max \left(a_{i j}\right)-\min \left(a_{i j}\right)}, \text { for beneficial criteria } \\
& r_{i j}=\frac{\max \left(a_{i j}\right)-a_{i j}}{\max \left(a_{i j}\right)-\min \left(a_{i j}\right)}, \text { for non-beneficial criteria }
\end{aligned}
$$

Step 3: Determine performance differences between each pair of alternatives with respect to each criterion

$$
d_{j}(a, b)=g_{j}(a)-g_{j}(b)
$$

Where $g_{j}(a)$ and $g_{j}(b)$ show the performance of alternatives a and $\mathrm{b}$, respectively, with regard to criterion $\mathrm{j}$, and $d_{j}(a, b)$ denotes the difference between these performances. 
Step 4: Calculate the preference function

$$
p_{j}(a, b)=d_{j}(a, b), \text { for } d_{j}(a, b) \geq 0, j=1,2, \ldots, n \& \forall a, b \in A
$$

$p_{j}(a, b)=0$, for $d_{j}(a, b)<0$

Step 5: Calculation of aggregated preference indices: for each pair of alternatives, an aggregated preference index is calculated as follows:

$$
\Pi(a, b)=\sum_{j=1}^{n} p_{j}(a, b) w_{j}, \forall a, b \in A
$$

Where $\Pi(a, b)$ denotes the overall preference of $a$ over $b$, and $w_{j}$ is the weight associated with the $j^{\text {th }}$ criterion.

Step 6: Calculate the net outranking flows: for each alternative $a$ when compared with $(n-1)$ other alternatives in $A$, positive and negative outranking flows or the leaving \& entering outranking flows are calculated as follows:

$$
\begin{aligned}
& \phi^{+}(a)=\frac{1}{n-1} \sum_{x \in A} \Pi(a, x), \text { for each } a \\
& \phi^{-}(a)=\frac{1}{n-1} \sum_{x \in A} \Pi(a, x), \text { for each } a
\end{aligned}
$$

Where $\phi^{+}(a)$ and $\phi^{-}(a)$ denote the positive and negative outranking flow for alternative $a$, respectively. A positive outranking flow of alternative $a$, indicates the overall outranking degree of this alternative, indicating the extent to which this alternative dominates all other alternatives. Similarly, a negative outranking flow of alternative $a$, indicates the extent to which this alternative is dominated by all other alternatives.

Step 7: Determine the ranking of all the considered alternatives depending on the values of $\phi(a)$.

$$
\phi(a)=\phi^{+}(a)-\phi^{-}(a), \text { for each } a \quad, \phi(a) \epsilon[-1,1]
$$

Step 8: Rank the alternatives, sorting by the values $\phi(a)$, in decreasing order. 


\subsubsection{VIKOR: VIšekriterijumsko KOmpromisno Rangiranje}

The VIKOR method has been developed for the optimization of complex systems by multi-criteria. It specifies the compromise ranking list, the compromise solution, and the weight stability intervals for the compromise solution obtained with the initial (given) weights preference stability (Opricovic 1998). In the VIKOR model, compromise ranking can be performed by comparing the measure of closeness to the ideal solution (Chitsaz and Banihabib 2015).

The compromise ranking algorithm VIKOR has the following steps and the equations are based on (Opricovic and Tzeng 2004):

Step 1: Construct the decision matrix and determine the weight of criteria

Step 2: Determine the best $\left(X_{i}^{+}\right)$and the worst $\left(X_{i}^{-}\right)$values of all criteria

$$
\begin{aligned}
& X_{i}^{+}=t_{j}^{\max }, \text { for } j \epsilon \text { beneficial criteria } \\
& X_{i}^{+}=t_{j}^{\text {min }}, \text { for } j \epsilon \text { non-beneficial criteria } \\
& X_{i}^{-}=t_{j}^{\text {min }}, \text { for } j \epsilon \text { beneficial criteria } \\
& X_{i}^{-}=t_{j}^{\text {max }}, \text { for } j \epsilon \text { non-beneficial criteria }
\end{aligned}
$$

Step 3: Calculate the normalized decision matrix

The VIKOR method uses linear normalization.

$$
r_{i j}=\frac{\left(X_{i}^{+}-a_{i j}\right)}{\left(X_{i}^{+}-X_{i}^{-}\right)}
$$

Step 4: Calculate the weighted normalized decision matrix

$$
t_{i j}=r_{i j} \cdot w_{j}
$$

Step 5: Compute the values $S_{i}$ and $R_{i}, i=1,2, \ldots, m$, by the relations

$$
S_{i}=\sum_{j=1}^{n} w_{j}\left(X_{i}^{+}-a_{i j}\right) /\left(X_{i}^{+}-X_{i}^{-}\right)
$$




$$
R_{i}=\max \left[w_{j}\left(X_{i}^{+}-a_{i j}\right) /\left(X_{i}^{+}-X_{i}^{-}\right)\right]
$$

Where $w_{j}$ are the weights of criteria, expressing their relative importance.

Step 6: Compute the values $Q_{i}, \mathrm{i}=1,2, \ldots, \mathrm{m}$, by the relation

$$
Q_{i}=v\left(S_{i}-S^{*}\right) /\left(S^{-}-S^{*}\right)+(1-v)\left(R_{i}-R^{*}\right) /\left(R^{-}-R\right)
$$

Where $S^{*}=\min S_{i}, S^{-}=\max S_{i}, R^{*}=\min R_{i}, R^{-}=\max R_{i}$, and $v$ is introduced as weight of the strategy of "the majority of criteria", mostly the value of $v$ is set as

0.5. However, $v$ can set any value from 0 to 1.

Step 7: Rank the alternatives, sorting by the values $Q_{i}$, in decreasing order.

\subsubsection{Methods Comparison}

MCDA methods used in our analysis include WSM, TOPSIS, PROMETHEE II, and VIKOR, simultaneously. Each method has its own characteristics, varying levels of sophistication, and advantages/disadvantages and none of the methods dominates the other methods. The choice of an effective method depends mostly on the analyst's preferences. However, more than one method can be used to solve the same multi-criteria decision problem and provide more robust decision information (Mulliner, Malys, and Maliene 2016). Although the selected methods for the comparative analysis differ in their basic principles, all MCDA methods follow three stages as following (Triantaphyllou 2000):

- Determine criteria and alternatives

- Determine the weight of the criteria and the impacts of the alternative on these criteria

- Determine the ranking of alternatives with different computational mechanisms 
Table 7: The Comparisons of Four MCDM Methods in the Study

\begin{tabular}{ccccc}
\hline & WSM & TOPSIS & PROMETHEE II & VIKOR \\
\hline Feature & $\begin{array}{c}\text { Simple and easy } \\
\text { to handle } \\
\text { problems in } \\
\text { decision making } \\
\text { with multiple } \\
\text { criteria }\end{array}$ & $\begin{array}{c}\text { Consideration of } \\
\text { both } \\
\text { ideal-best and } \\
\text { ideal-worst } \\
\text { solutions }\end{array}$ & $\begin{array}{c}\text { Maximize group } \\
\text { benefits and } \\
\text { minimize } \\
\text { bairwise comparison } \\
\text { bandividual regret, } \\
\text { fonctions } \\
\text { makers can } \\
\text { consider } \\
\text { consensus } \\
\text { solutions more } \\
\text { easily }\end{array}$ \\
\hline Calculation Procedure & Easy & Medium & Complex & Medium \\
\hline Normalization & Max normalization & Vector & Max-Min & Linear \\
normalization & normalization & normalization
\end{tabular}

Table 7 shows the comparisons of four MCDM methods used in this study. The selected methods for the comparative analysis vary in their basic principles. As can be seen from Table 7, the methods use different kinds of normalization to eliminate the units of criterion functions, and the level of difficulty of each method are different.

\subsection{Application of the framework: A Case Study of Mountain line Transit Authority (MLTA)}

Mountain Line Transit Authority, founded in 1996, is the primary transit provider in and surrounding Morgantown and Monongalia County, located in West Virginia, home to over 106000 people ("U.S. Census Bureau QuickFacts: West Virginia” 2019). MLTA provides transit service to WVU as well as localized service around Morgantown. MLTA connects to areas outside Monongalia County, including Fairmont (WV), Clarksburg (WV), Waynesburg (PA), and Pittsburgh (PA). A portion of the agency's service is geared towards the campus's needs due to the large student population of West Virginia University. The agency provides slightly reduced service when school is not in session. MLTA's service is deviated fixed route, with opportunities for customers to apply in advance for deviated locations along routes. The headquarters are Westover, West Virginia, and is home to the administrative office, bus garage, and shop.

Along with the administrative staff, MLTA also has a Board of Directors and Citizens Advisory Committee. The agency of MLTA began as a consolidation between the city of Morgantown and a county-wide system and currently operates three park and ride locations: Westover, Granville, and Cheat Lake. There is limited conventional transit infrastructure in place 
due to the topography and tight street environment. Bus shelters and bus stop signs are not predominant throughout the system since most routes operate with a flag down system. Flag stops allow customers to catch a bus anywhere along a route that provides a safe waiting environment and safe stopping point for the bus.

MLTA has been strategically extending service and operating to connect the region more efficiently and effectively, working with area partners to provide additional mobility benefits to the greater region. As part of these strategic efforts, MLTA is working on some short to mediumterm transit plans to identify necessary changes, enhancements, or expansion to continue quality service for current riders while attracting more riders to the system. The plan will look to effectively orient the agency and its transit service for the future. The transit service provided by MLTA plays a highly significant role in the community's overall transportation picture. MLTA is one of the majority of transit authorities that look at the partnerships between transit agencies and transportation network companies (TNCs) to provide customers with mobility options. This study aims to help MLTA to evaluate adopting a ridehailing program and, therefore, more easily achieve its goals and improve its effectiveness.

\subsubsection{Defining Criteria and Alternatives}

The ridehailing programs and used criteria for evaluation of different ridehailing programs were suggested from the literature, taking into consideration the availability of data, and finalized through interview meeting with decision-makers of the MLTA service providers. Firstly, we reviewed the literature, especially TRB's Transit Cooperative Research Program (TCRP) Research Report 204, which provides the latest information for transit practitioners, Public and private sectors, and how they should be partnered (Board and National Academies of Sciences 2019). The report provided comprehensive guidance for both parties based on 20 case studies of partnerships between transit agencies and TNCs. 
Table 8: Criteria Suggested to Select the Best Ridehailing Programs

\begin{tabular}{|c|c|c|}
\hline Ref. & Criteria & Clarification \\
\hline \multirow{14}{*}{$\begin{array}{l}\text { (Board and National } \\
\text { Academies of } \\
\text { Sciences 2019) }\end{array}$} & Cost of ridehailing program & \multirow{9}{*}{$\begin{array}{l}\text { Common metrics for the evaluation of } \\
\text { agency's transit-TNC program }\end{array}$} \\
\hline & Other operating expenses & \\
\hline & System-wide ridership & \\
\hline & Demographic makeup of participants & \\
\hline & Offering an alternative to paratransit & \\
\hline & Providing a guaranteed ride home & \\
\hline & Customer satisfaction & \\
\hline & Geographic coverage & \\
\hline & Passengers' waiting time & \\
\hline & Service hours & $\begin{array}{c}\text { One of the reasons to enter partnership } \\
\text { due to short service hours }\end{array}$ \\
\hline & Offering peak -hour mobility services & \multirow{4}{*}{$\begin{array}{c}\text { The primary goals for transit agencies } \\
\text { in developing a TNC } \\
\text { partnership/collaboration }\end{array}$} \\
\hline & $\begin{array}{c}\text { Offering off-peak -hour mobility } \\
\text { services }\end{array}$ & \\
\hline & First/last mile services & \\
\hline & $\begin{array}{r}\text { Providing mobility options in } \\
\text { suburban/rural areas }\end{array}$ & \\
\hline (Bok and Kwon 2016) & Accessibility & $\begin{array}{l}\text { Population with access to public } \\
\text { transit services }\end{array}$ \\
\hline (Shoup 2017) & $\begin{array}{c}\text { Impact on traffic congestion and/or } \\
\text { parking demand }\end{array}$ & \multirow{3}{*}{ Environmental and social indicators } \\
\hline $\begin{array}{l}\text { (Godavarthy, Mattson, } \\
\text { and Ndembe 2014) }\end{array}$ & Emission reduction & \\
\hline (Welch 2013) & Access to health services & \\
\hline
\end{tabular}

Table 8 shows the initial suggested criteria to evaluate adopting a ridehailing program. In the following, we discuss how we finalize the criteria. 
Table 9: Criteria Used to Select the Best Ridehailing Programs

\begin{tabular}{ll}
\hline $\mathbf{C}_{\mathbf{j}}$ & Criteria \\
\hline $\mathrm{C}_{1}$ & Other operating expenses \\
\hline $\mathrm{C}_{2}$ & Cost of ride-hailing program \\
\hline $\mathrm{C}_{3}$ & System-wide ridership (including the riders of ride-hailing program) \\
\hline $\mathrm{C}_{4}$ & Geographic coverage (i.e., service area) \\
\hline $\mathrm{C}_{5}$ & Accessibility (i.e., population with access to public transit services) \\
\hline $\mathrm{C}_{6}$ & First/last mile services \\
\hline $\mathrm{C}_{7}$ & Access to health services \\
\hline $\mathrm{C}_{8}$ & Service hours \\
\hline $\mathrm{C}_{9}$ & Passengers' waiting time \\
\hline $\mathrm{C}_{10}$ & Customer satisfaction \\
\hline $\mathrm{C}_{11}$ & Providing peak-hour mobility services \\
\hline $\mathrm{C}_{12}$ & Providing off peak-hour mobility services \\
\hline $\mathrm{C}_{13}$ & Providing mobility options in suburban/rural areas \\
\hline $\mathrm{C}_{14}$ & Demographic makeup of participants \\
\hline $\mathrm{C}_{15}$ & Impact on traffic congestion and/or parking demand \\
\hline
\end{tabular}

Table 9 represents confirmed criteria by decision-makers of MLTA through the interview meeting. Based on the input of the decision-makers of MLTA in pre-survey and interview, three criteria, namely "Offering an alternative to paratransit", "Providing a guaranteed ride home", and "Emission reduction" were eliminated. The participants believed that people with disabilities were not the target customers of MLTA, and a guaranteed ride home overlaps the criterion "First/last mile services". Besides, environmental impacts (e.g., emission reduction) are not a major concern in small urban areas.

Besides, we suggested the following three alternative service models (i.e., types of service) that MLTA agency might be interested in establishing. "First mile/last mile connections to fixed routes", "Late night (or early morning) service options", and "Providing on-demand service options". For "Providing on-demand service options", the participants received 
suggestions and they could select the service that would best meet their agency's goals or describe an alternative service.

$>$ Providing on-demand service for the general public anywhere in Monongalia County.

$>$ Providing on-demand service for a specific population segment anywhere in Monongalia County (e.g., substituting the current program NewFIT).

$>$ Providing on-demand service for the general public in areas of Monongalia County where there is no access to fixed routes.

$>$ Substituting low-frequency fixed-route services with on-demand service for the general public in areas previously serviced by the fixed route.

Finally, we ended up with five scenarios, including a base scenario and four alternatives:

$>$ A0 - Do nothing: Base scenario; Current situation; As-Is situation.

$>\mathrm{A} 1$ - First/Last mile: Providing first/ last mile connections to and from different locations (transit centers, or intersections with transit service) throughout Monongalia County.

$>$ A2 - Late night/Early morning: Providing overnight door to door rides throughout Monongalia County (10 pm to $6 \mathrm{am})$.

$>$ A3 - On-Demand (low-frequency fixed routes): Substituting low-frequency fixedroute services with on-demand service for the general public in areas previously serviced by the fixed route.

$>$ A4 - On-Demand (non-coverage): Providing on-demand service for the general public in areas of Monongalia County where there is no access to fixed routes.

\subsubsection{Data Collection}

The stakeholders of MLTA were invited to participate in an interview focusing on evaluating of different service models/ridehailing programs for a potential future partnership between MLTA and a transportation network company (TNC), such as Lyft or Uber. We collected data through a pre survey, interviews, and allowed participants to revise if needed. The study was acknowledged by WVU IRB (Protocol \#2006041456). Before interviewing with decision-makers, the participants were given a through explanation of the purpose of the study and data collection procedure. The participants' signature was then obtained on an IRB consent form. 
During the interview, three main topics were discussed:

- The selection of criteria MLTA would consider when assessing a potential ridehailing program

- The importance of each criterion MLTA would consider when assessing a potential ridehailing program

- Assessment of potential ridehailing programs with respect to the different criteria identified

Due to the COVID-19 pandemic, we were not able to have interviews with more staff of MLTA and we could just capture the opinions of the CEO and the mobility manager of MLTA (Two participants).

In this study, we use qualitative criteria with points unit of measurement only. The participants were asked to estimate the potential of different ridehailing programs with respect to different criteria identified based on objective and perceived comparative benefits and costs.

\subsection{Case Study Results and Discussion}

\subsubsection{Weighted Criteria}

The weight of each criterion, which expresses the relative importance of the criteria, is calculated as discussed in the subsection of "Weighting of Criteria". To obtain weight of criteria we asked decision-makers to rate each criterion using a scale of importance ranging from 1 to 5 (1: not at all important to extremely important) (Işıklar and Büyüközkan 2007). 
Table 10: Weighted Criteria

\begin{tabular}{|c|c|c|c|}
\hline $\mathbf{C}_{\mathbf{j}}$ & Criteria & $\begin{array}{r}\text { Avg } \\
\text { Rating }\end{array}$ & Weight \\
\hline $\mathrm{C}_{5}$ & Accessibility (i.e., population with access to public transit services) & 4.5 & 0.096 \\
\hline $\mathrm{C}_{6}$ & First/last mile services & 4.5 & 0.096 \\
\hline $\mathrm{C}_{1}$ & Other operating expenses & 4 & 0.085 \\
\hline $\mathrm{C}_{2}$ & Cost of ride-hailing program & 4 & 0.085 \\
\hline $\mathrm{C}_{10}$ & Customer satisfaction & 4 & 0.085 \\
\hline $\mathrm{C}_{13}$ & Providing mobility options in suburban/rural areas & 4 & 0.085 \\
\hline $\mathrm{C}_{3}$ & System-wide ridership (including the riders of ride-hailing program) & 3.5 & 0.074 \\
\hline $\mathrm{C}_{8}$ & Service hours & 3.5 & 0.074 \\
\hline $\mathrm{C}_{14}$ & Demographic makeup of participants & 3 & 0.064 \\
\hline $\mathrm{C}_{7}$ & Access to health services & 2.5 & 0.053 \\
\hline $\mathrm{C}_{9}$ & Passengers' waiting time & 2.5 & 0.053 \\
\hline $\mathrm{C}_{4}$ & Geographic coverage (i.e., service area) & 2 & 0.043 \\
\hline $\mathrm{C}_{12}$ & Providing off peak-hour mobility services & 2 & 0.043 \\
\hline $\mathrm{C}_{11}$ & Providing peak-hour mobility services & 1.5 & 0.032 \\
\hline $\mathrm{C}_{15}$ & Impact on traffic congestion and/or parking demand & 1.5 & 0.032 \\
\hline
\end{tabular}

Table 10 shows weighted criteria in decreasing order. To calculate criteria weights, the mean rating of importance obtained for each criterion was divided by the number of the mean scores, such that the total of all weights is equal to one.

\subsubsection{Decision Matrix}

In order to evaluate ridehailing programs, we defined the criteria and scoring method using a matrix. Here, to build the decision matrix, we investigated data by asking stakeholders of MLTA to rate different scenarios with respect to each criterion. The higher the rating value, the higher the variant scores in the ranking. It should be noted that in MCDA computation steps, we treated all criteria as beneficial criteria. For example, for cost, in essence non beneficial criterion, we considered higher rate for a program which had lower cost and lower rate for a program which had higher cost. Using the previously estimated weights of decision factors and the average variant scores in the ranking of decision variants, a multi-criteria analysis of the variants will be made in 
accordance with the WSM, TOPSIS, PROMETHEE II, and VIKOR method algorithms. All criteria are measured on a five-point scale (1: Poor to 5: Excellent). We instructed the participants to rate A0, considering not the absolute performance of the current system but the room for improvement. Therefore, the performance ratings of A0 do not correspond to the respondents' opinion of the absolute performance of MLTA services in any way.

Table 11: Initial Decision Matrix for MCDA with All Criteria Considered as Benefit Criteria

\begin{tabular}{ccccccc}
\hline $\mathbf{C}_{\mathbf{j}}$ & $\mathbf{W}_{\mathbf{j}}$ & $\mathbf{A 0}$ & $\mathbf{A 1}$ & $\mathbf{A 2}$ & $\mathbf{A 3}$ & $\mathbf{A 4}$ \\
\hline $\mathrm{C}_{1}$ & 0.085 & 3 & 3.5 & 3 & 4 & 3 \\
\hline $\mathrm{C}_{2}$ & 0.085 & 4 & 3 & 2 & 4 & 2 \\
\hline $\mathrm{C}_{3}$ & 0.074 & 3 & 4 & 4 & 4.5 & 4.5 \\
\hline $\mathrm{C}_{4}$ & 0.043 & 2.5 & 4 & 4 & 4.5 & 4.5 \\
\hline $\mathrm{C}_{5}$ & 0.096 & 2.5 & 4.5 & 4 & 4 & 4.5 \\
\hline $\mathrm{C}_{6}$ & 0.096 & 2 & 4 & 2.5 & 3.5 & 4 \\
\hline $\mathrm{C}_{7}$ & 0.053 & 3.5 & 4 & 4 & 4.5 & 4.5 \\
\hline $\mathrm{C}_{8}$ & 0.074 & 3.5 & 3.5 & 4.5 & 4.5 & 4.5 \\
\hline $\mathrm{C}_{9}$ & 0.053 & 2.5 & 4 & 4 & 5 & 5 \\
\hline $\mathrm{C}_{10}$ & 0.085 & 2 & 4 & 4 & 5 & 5 \\
\hline $\mathrm{C}_{11}$ & 0.032 & 3.5 & 4.5 & 3.5 & 4.5 & 4.5 \\
\hline $\mathrm{C}_{12}$ & 0.043 & 2 & 3.5 & 4 & 4 & 4 \\
\hline $\mathrm{C}_{13}$ & 0.085 & 2 & 3.5 & 4 & 4 & 4.5 \\
\hline $\mathrm{C}_{14}$ & 0.064 & 2.5 & 4 & 4 & 4.5 & 4.5 \\
\hline $\mathrm{C}_{15}$ & 0.032 & 3.5 & 4.5 & 3.5 & 3.5 & 3.5
\end{tabular}

Table 11 shows the $\mathrm{N} \times \mathrm{M}$ matrix $\mathrm{A}$ has data entries $a_{i j}$ corresponding to the value of the ith (of $\mathrm{M}$ ) alternatives in terms of the jth (of $\mathrm{N}$ ) decision criterion, and $W_{j}$ is the weight (importance) of the jth criterion. To obtain Table 11, we consider the average weights of the criteria and average perceived ratings of each alternative with respect to each criterion according to stakeholders' opinions. In other words, equal weight was assigned to each expert.

The comparative performance of several appropriate MCDA methods - the WSM, TOPSIS, PROMETHEE II, and VIKOR - is investigated in this study. These techniques are 
applied to the practical case study data contained in the initial decision-making matrix (e.g., Table 11). The goal is to evaluate the relative importance of each alternative under consideration using each approach, as well as to evaluate the priority order of the alternatives with respect to each other. Therefore the decision making situation is a ranking problem where alternatives need to be ranked from best to worst. As mentioned earlier, the methods chosen for comparative analysis differ in their basic principles, the type of data normalization process, and how they combine the criteria values and the weights of the criteria into the evaluation procedure.

\subsubsection{Equal Weights Assigned to Decision-Makers (DMs)}

Table 12: Data Obtained by Ranking of the Alternatives Using Various MCDA Methods

\begin{tabular}{lccccc} 
& \multicolumn{5}{c}{ Alternatives } \\
\hline & A0 & A1 & A2 & A3 & A4 \\
\hline WSM & 5 & 3 & 4 & 1 & 2 \\
\hline TOPSIS & 5 & 3 & 4 & 1 & 2 \\
\hline PROMETHEE II & 5 & 3 & 4 & 1 & 2 \\
\hline VIKOR & 5 & 2 & 4 & 1 & 3
\end{tabular}

As shown in Table 12, On-Demand (low-frequency fixed routes) alternative (A3) was the perceived optimal alternative in all four MCDA methods - the WSM, TOPSIS, PROMETHEE II, and VIKOR. It seems that the optimal alternative for transit-ridehailing partnership is substituting low-frequency fixed-route services with on-demand service for the general public in areas previously serviced by the fixed route. The results are likely driven by the fact that the stakeholders of MLTA are currently exploring different alternative service models for MLTA's low-frequency low-demand fixed-routes (such as Crown, Mountain Heights, Grafton Rd), because such routes, due to the relatively low demand, are less cost-effective. The results in Table 12 also indicate that all ridehailing programs outperform the base scenario (A0). This finding implies that the respondents identified merits in establishing any of the assessed ridehailing program. The Late night/Early morning program (A2) ranked lowest among all four ridehailing programs. The other two alternatives, On-Demand (non-coverage) program (A4) and First/Last Mile program (A1) ranked second and third, respectively in the WSM, TOPSIS, and PROMETHEE II methods. Only VIKOR method, concluded that the second alternative could be First/Last Mile program (A1) and On-Demand (non-coverage) program (A4) as $3^{\text {rd }}$ priority while the other three methods represented the $2^{\text {nd }}$ option could be the Demand (non-coverage) program 
(A4) and the third-ranked alternative could be First/Last Mile program (A1). The result is surprising since two of the most common motivation behind transit- ridehailing partnership are helping people connect to transit stations and people with late night travel needs (Board and National Academies of Sciences 2019). Nevertheless, our findings show that people traveling in lower density environments could be the most common target audiences in small urban areas. It seems that MLTA already provides the coverage desired based on the agencies and local planning goals. However, if a large area located north of WV 705 (currently undeveloped forest land) develops, it would require additional transit routes, or new pathway connections to existing transit routes, to be served (“2013-2040 Long Range Transportation Plan” 2014, 51).

\subsubsection{Different Weights Assigned to Decision-Makers (DMs)}

In practice, several decision-making processes occur with incomplete information in group settings (Xu and Chen 2007). In such a complex environment, decision-makers (DMs) have specific expertise, proficiency and experiences. Therefore, for each attribute, the group can assign different rate of importance to each expert. In the following, results based on different weights to stakeholders of MLTA can be seen.

Table 13: Data Obtained by Ranking of the Alternatives Using Various MCDA Methods and Assigning Different Weights to DMs

\begin{tabular}{|c|c|c|c|c|c|}
\hline & \multicolumn{5}{|c|}{ Alternatives } \\
\hline & A0 & $\mathrm{A} 1$ & A2 & A3 & A4 \\
\hline WSM(50\%-50\%) & 5 & 3 & 4 & 1 & 2 \\
\hline TOPSIS(50\%-50\%) & 5 & 3 & 4 & 1 & 2 \\
\hline PROMETHEE(50\%-50\%) & 5 & 3 & 4 & 1 & 2 \\
\hline VIKOR(50\%-50\%) & 5 & 2 & 4 & 1 & 3 \\
\hline $\operatorname{WSM}(70 \%-30 \%)$ & 5 & 3 & 4 & 1 & 2 \\
\hline TOPSIS(70\%-30\%) & 5 & 3 & 4 & 1 & 2 \\
\hline PROMETHEE(70\%-30\%) & 5 & 3 & 4 & 1 & 2 \\
\hline VIKOR(70\%-30\%) & 5 & 3 & 4 & 1 & 2 \\
\hline
\end{tabular}


Assigning a higher weight to one of the decision-makers (here, e.g., CEO) will likely result in rankings that are closer to the perceptions of that decision-maker. The results here are included only for illustration purposes. This method of assigning different weights to different DMs can be used when there are multiple decision-makers, ranging from highly positioned people to those in lower level positions. By doing so, we can give a voice to each stakeholder, but with different weights to keep the difference between their expertise and preferences. Table 13 shows that in our analysis, the results did not significantly change after assigning different weights to decisionmakers. This can be due to having only two participants with similar opinions.

\subsection{Conclusions}

In this study, we developed an analytical approach to help transit agencies in rural and small urban communities to evaluate adopting a ridehailing program, and therefore, more easily achieve their goals and improve their effectiveness. The proposed methods were used to evaluate ridehailing program options for Mountain Line Transit Authority (MLTA), which operates in Monongalia County, WV, and is currently considering to establish a ridehailing program. The findings show that On-Demand (low-frequency fixed routes) alternative (A3) ranked first and OnDemand (non-coverage) program (A4) ranked second in all four MCDA methods - the WSM, TOPSIS, PROMETHEE II, and VIKOR. Based on this analysis, the optimal alternative for transitridehailing partnership is substituting low-frequency fixed-route services with on-demand service for the general public in areas previously serviced by the fixed route. Beside, we found that employing any of these four alternatives would improve the current situation of MLTA. Based on the results of our analysis, the third, fourth-ranked alternatives could be First/Last Mile program (A1) and the Late night/Early morning program (A2), respectively. These two programs are considered the most common ridehailing programs which are helping people connect to transit stations and people with late night travel needs (Board and National Academies of Sciences 2019). Nevertheless, our findings show that people traveling in lower density environments could be the most common target audiences in small urban areas.

The results must be interpreted with caution, and a number of limitations should be borne in mind. Firstly, the study focused on qualitative variables (criteria) which are heavily expertdependent and may be highly subjective. Only two experts participated in our study and their estimates may be conservative and an overestimation of the base scenario referring to the current 
situation of the MLTA. Specifically, the decision of including A0 (or the current situation) in combination with the wording used to assess the performance of each program with respect to each of the criteria (i.e., How would you rate [program $\mathrm{xxx}$ ] with respect to [criterion $\mathrm{xxx}$ ?) resulted in a left skewed distribution of performance ratings. In the data collection interview, it was clarified that the performance evaluation of A0 does not correspond to an evaluation of the current performance of the transit services in absolute terms but should reflect the potential for improvement. Nevertheless, the rating of the current services across all criteria was a 2.8, which resulted in the capture of relatively small variations in the other different scenarios (for example, an improvement from A0 to an alternative could be captured with a rating of 3, 4, or 5 for all of the criteria or only with a rating of 4 or 5 for many of the criteria). Future research can explore different designs of the data collection instrument that do not explicitly involve the performance evaluation of current services and/or the use of a measurement scale with more than 5-points (for example a 10-point scale can be used).

The second limitation of our analysis is that we used only point measurement for criteria and stakeholders' perceived rating of each alternative with respect to each criterion. In our future work, we are trying to look at the same problem with a different point of view and fix our shortages. As an illustration, some criteria such as operating cost, cost of ridehailing program, ridership, geographic coverage, accessibility, service hours, and passengers' waiting time can be quantified by different units of measure. Criteria values could be calculated with more relevant units of measure by making relevant assumptions for each alternative. Therefore, in our future research, we will determine the decision matrix for the comprehensive assessment of adopting ridehailing programs. Then, we could easily compare the result with our current result of alternatives rankings. 


\section{Section 4}

\section{Conclusions and Future Research}

In this thesis, we applied operations research and decision-making tools to two public transit projects in small urban and rural areas. The first project focused on three models developed to evaluate the efficiency, effectiveness, and combined efficiency-effectiveness of rural transit agencies using data envelopment analysis. The models were estimated for the case study of transit systems in rural Appalachia and measured the agencies' performance relative to their peers. Besides, the returns to scale were explored in the context of rural transit management. The second project focused on employing ridehailing programs in small urban and rural areas to improve agencies' performance and reach. We suggested the most relevant criteria to evaluate the performance of different ridehailing programs using Multi-Criteria Decision Analysis methodology. To perform a set of MCDA methods, we used the perceived rating of each ridehailing program according to the stakeholders' opinions with respect to each criterion. The framework was estimated for the case study of Mountain Line Transit Authority in Morgantown, WV.

The findings of the first project have several implications. The efficiency and effectiveness of transit systems were not necessarily related. Besides, combined efficiency-effective seemed to be more strongly affected by the output produced (e.g., vehicle miles) than the output consumed (e.g., passenger trips). Such findings suggested the need to analyze rural transit systems in a comprehensive way and in more than one aspect, in practice. With regard to regional planning, the findings showed that, overall, Appalachian rural agencies were more efficient than they were effective. Indeed, many of the systems appeared to be far less effective than they could be (relative to their peers).

Although using a small dataset, the results indicated that the DEA methodology was an effective and informative peer assessment tool that could be used to determine the performance of rural transit systems. It should be stated that although the case study in this study focused on rural Appalachia, due to the structured data collection provided by the FTA and iNTD reporting procedures, the suggested methodology is easily transferable to any rural area in the U.S for future study. In addition, while this study used data from a single year, an analysis could be performed using panel data. On top of this, an investigation of external factors that could affect transit 
efficiency, such as population density and other socio-economic and demographic characteristics, distance of the subject area from an urban center, or the accessibility of services, may also provide useful insights. Finally, such an investigation could be conducted using DEA methodologies (e.g., second-stage DEA) or standard econometric techniques.

In the second study, the comparative performance of several appropriate MCDA methods - the WSM, TOPSIS, PROMETHEE II, and VIKOR - was investigated. The goal was to evaluate the relative importance of each alternative/ridehailing program under consideration using each approach and evaluate the priority order of the alternatives with respect to each other. All MCDA methods used in our analysis showed that the perceived optimal alternative for the transitridehailing partnership was substituting low-frequency fixed-route services with on-demand service for the general public in areas previously serviced by the fixed route. We also suggested assigning different weights to decision-makers since decision-makers (DMs) have specific expertise, proficiency, and experiences in the real world. Therefore, against an attribute, the group can assign a different rate of importance to each expert. Future research could improve by increasing the number of participants and assigning different weights to decision-makers. 


\section{References}

“2013-2040 Long Range Transportation Plan.” 2014. https://7b684dee-1ab5-4616-99929d54880108cf.filesusr.com/ugd/613794_6f59697935b54700867d6bb444223589.pdf.

Arman, Mohammad, and Samuel Labi. 2013. "Efficiency of Indiana Fixed Route Transit Agencies Using Data Envelopment Analysis."

Arman, Mohammad, Samuel Labi, and Kumares C. Sinha. 2012. "An Assessment of the Operational Performance of Public Transit Agencies Using Data Envelopment Analysis (DEA) Technique.” In , 30-37. Washington DC, United States.

— 2013. "Perspectives of the Operational Performance of Public Transportation Agencies with Data Envelopment Analysis Technique." Transportation Research Record 2351 (1): 30-37.

Arndt, Jeffrey, and Suzie Edrington. 2011. "Rural and Urban Transit District Benchmarking: Effectiveness and Efficiency Guidance Document."

Banker, Rajiv D., Abraham Charnes, and William Wager Cooper. 1984. "Some Models for Estimating Technical and Scale Inefficiencies in Data Envelopment Analysis." Management Science 30 (9): 1078-92.

Banker, Rajiv D., and Robert M. Thrall. 1992. "Estimation of Returns to Scale Using Data Envelopment Analysis." European Journal of Operational Research 62 (1): 74-84.

Barnum, Darold T., Matthew G. Karlaftis, and Sonali Tandon. 2011. "Improving the Efficiency of Metropolitan Area Transit by Joint Analysis of Its Multiple Providers." Transportation Research Part E: Logistics and Transportation Review 47 (6): 1160-76.

Behzadian, Majid, Reza Baradaran Kazemzadeh, Amir Albadvi, and Mohammad Aghdasi. 2010. "PROMETHEE: A Comprehensive Literature Review on Methodologies and Applications." European Journal of Operational Research 200 (1): 198-215.

Board, Transportation Research, and Engineering National Academies of Sciences. 2019. "Partnerships Between Transit Agencies and Transportation Network Companies." Washington, DC: The National Academies Press. https://www.nap.edu/catalog/25425/partnerships-between-transit-agencies-andtransportation-network-companies.

Boilé, Maria P. 2001. "Estimating Technical and Scale Inefficiencies of Public Transit Systems." Journal of Transportation Engineering 127 (3): 187-94.

Bok, Jinjoo, and Youngsang Kwon. 2016. "Comparable Measures of Accessibility to Public Transport Using the General Transit Feed Specification." Sustainability 8 (3): 224.

Broniewicz, Elzbieta, and Karolina Ogrodnik. 2020. "Multi-Criteria Analysis of Transport Infrastructure Projects." Transportation Research Part D: Transport and Environment 83: 102351.

Chames, Abraham, William W. Cooper, and Edwardo Rhodes. 1978. "Measuring the Efficiency of Decision Making Units." European Journal of Operational Research 2 (6): 429-44.

Chitsaz, Nastaran, and Mohammad Ebrahim Banihabib. 2015. "Comparison of Different Multi Criteria Decision-Making Models in Prioritizing Flood Management Alternatives.” Water Resources Management 29 (8): 2503-25.

Chu, Xuehao, Gordon J. Fielding, and Bruce W. Lamar. 1992. "Measuring Transit Performance Using Data Envelopment Analysis." Transportation Research Part A: Policy and Practice 26 (3): 223-30. 
Cooper, William W., Lawrence M. Seiford, and Kaoru Tone. 2007. "Data Envelopment Analysis: A Comprehensive Text with Models, Applications, References and DEA-Solver Software: Springer Science \& Business Media." New York, USA.

Ellis, Elizabeth H., and Brian E. McCollom. 2009. Guidebook for Rural Demand-Response Transportation: Measuring, Assessing, and Improving Performance. Vol. 136. Transportation Research Board.

Fielding, Gordon J., Roy E. Glauthier, and Charles A. Lave. 1978. "Performance Indicators for Transit Management." Transportation 7 (4): 365-79.

Fishburn, Peter C. 1967. "Letter to the Editor-Additive Utilities with Incomplete Product Sets: Application to Priorities and Assignments." Operations Research 15 (3): 537-42.

Garrett, Mark. 2014. Encyclopedia of Transportation: Social Science and Policy. SAGE Publications.

Georgiadis, Georgios, Ioannis Politis, and Panagiotis Papaioannou. 2014. "Measuring and Improving the Efficiency and Effectiveness of Bus Public Transport Systems." Research in Transportation Economics 48: 84-91.

Godavarthy, Ranjit, Jeremy Mattson, and Elvis Ndembe. 2014. "Cost-Benefit Analysis of Rural and Small Urban Transit." University of South Florida, Tampa: National Center for Transit Research.

Hahn, Jin-Seok, Dong-Kyu Kim, Hyoung-Chul Kim, and Chungwon Lee. 2013. "Efficiency Analysis on Bus Companies in Seoul City Using a Network DEA Model." KSCE Journal of Civil Engineering 17 (6): 1480-88.

Hartman, Ronald J., Elaine M. Kurtz, and A. B. Winn. 1994. "TCRP Synthesis of Transit Practice 6: The Role of Performance-Based Measures in Allocating Funding for Transit Operations." Transportation Research Board, National Research Council, Washington, $D C$.

Hassan, Mohammad Nurul, Yaser E. Hawas, and Kamran Ahmed. 2013. "A Multi-Dimensional Framework for Evaluating the Transit Service Performance." Transportation Research Part A: Policy and Practice 50: 47-61.

Hwang, Ching-Lai, and Kwangsun Yoon. 1981. "Methods for Multiple Attribute Decision Making." In Multiple Attribute Decision Making, 58-191. Springer.

Iş1klar, Gülfem, and Gülçin Büyüközkan. 2007. "Using a Multi-Criteria Decision Making Approach to Evaluate Mobile Phone Alternatives." Computer Standards \& Interfaces 29 (2): 265-74.

Jahanshahloo, Gholam Reza, Majid Soleimani-Damaneh, and Mohsen Rostamy-Malkhalifeh. 2005. "An Enhanced Procedure for Estimating Returns-to-Scale in DEA." Applied Mathematics and Computation 171 (2): 1226-38.

Karlaftis, Matthew G. 2003. "Investigating Transit Production and Performance: A Programming Approach." Transportation Research Part A: Policy and Practice 37 (3): 225-40.

- 2004. "A DEA Approach for Evaluating the Efficiency and Effectiveness of Urban Transit Systems." European Journal of Operational Research 152 (2): 354-64.

Karlaftis, Matthew G., and Dimitrios Tsamboulas. 2012. "Efficiency Measurement in Public Transport: Are Findings Specification Sensitive?" Transportation Research Part A: Policy and Practice 46 (2): 392-402.

Lami, Isabella M. 2014. Analytical Decision-Making Methods for Evaluating Sustainable Transport in European Corridors. Vol. 11. Springer. 
Lao, Yong, and Lin Liu. 2009. "Performance Evaluation of Bus Lines with Data Envelopment Analysis and Geographic Information Systems." Computers, Environment and Urban Systems 33 (4): 247-55.

Lin, Wei-Feng, and Bao-cheng Zhang. 2010. "The Improved BCC RTS Method in Data Envelopment Analysis." In 2010 IEEE 17Th International Conference on Industrial Engineering and Engineering Management, 1613-17. IEEE.

Lockwood, Steve. 2004. "Transportation in Rural America: Challenges and Opportunities." In Oberstar Forum.

MacPherson, Hughes-Cromwick, and Matthew Dickens. 2019. "American Public Transportation Association (APTA) 2019 Public Transportation Fact Book." https://www.apta.com/wpcontent/uploads/APTA_Fact-Book-2019_FINAL.pdf.

Mattson, Jeremy. 2017. "Rural Transit Fact Book 2017." Western Transportation Institute.

Min, Hokey, Young-Hyo Ahn, and Thomas E. Lambert. 2015. "Evaluating the Comparative Efficiency of Urban Mass Transit Systems: A Longitudinal Analysis of the Ohio Case." International Journal of Logistics Research and Applications 18 (6): 518-34.

Min, Hokey, and Thomas E. Lambert. 2010. "Benchmarking and Evaluating the Comparative Efficiency of Urban Paratransit Systems in the United States: A Data Envelopment Analysis Approach." Journal of Transportation Management 21 (3): 6.

Mulliner, Emma, Naglis Malys, and Vida Maliene. 2016. "Comparative Analysis of MCDM Methods for the Assessment of Sustainable Housing Affordability." Omega 59: 146-56.

Nakanishi, Y. J., and J. R. Norsworthy. 2000. "Assessing Efficiency of Transit Service." In Proceedings of the 2000 IEEE Engineering Management Society. EMS-2000 (Cat. No. OOCH37139), 133-40. IEEE.

"National Transit Database (NTD) Glossary." 2015. Text. Federal Transit Administration. United $\begin{array}{lllll}\text { States Department of Transportation. August } 2015 . & .\end{array}$ https://www.transit.dot.gov/ntd/national-transit-database-ntd-glossary.

"National Transit Summary and Trends." 2017. https://www.transit.dot.gov/sites/fta.dot.gov/files/docs/ntd/130636/2017-national-transitsummaries-and-trends.pdf.

Nolan, J. F., P. C. Ritchie, and J. E. Rowcroft. 2002. "Identifying and Measuring Public Policy Goals: ISTEA and the US Bus Transit Industry." Journal of Economic Behavior \& Organization 48 (3): 291-304.

Nolan, James F. 1996. "Determinants of Productive Efficiency in Urban Transit." Logistics and Transportation Review 32 (3): 319.

Nolan, James Francis, Pamela C. Ritchie, and J. R. Rowcroft. 2001. "Measuring Efficiency in the Public Sector Using Nonparametric Frontier Estimators: A Study of Transit Agencies in the USA." Applied Economics 33 (7): 913-22.

Opricovic, Serafim. 1998. "Multicriteria Optimization of Civil Engineering Systems." Faculty of Civil Engineering, Belgrade 2 (1): 5-21.

Opricovic, Serafim, and Gwo-Hshiung Tzeng. 2004. "Compromise Solution by MCDM Methods: A Comparative Analysis of VIKOR and TOPSIS." European Journal of Operational Research 156 (2): 445-55.

Pollard, Kelvin, and Linda A. Jacobsen. 2018. "The Appalachian Region: A Data Overview from the 2012-2016 American Community Survey. Chartbook." Appalachian Regional Commission. 
Ripplinger, David. 2012a. "Organizing Transit in Small Urban and Rural Communities." North Dakota State University. . 2012b. "Organizing Transit in Small Urban and Rural Communities." North Dakota State University.

Sampaio, Breno Ramos, Oswaldo Lima Neto, and Yony Sampaio. 2008. "Efficiency Analysis of Public Transport Systems: Lessons for Institutional Planning." Transportation Research Part A: Policy and Practice 42 (3): 445-54.

Schwieterman, Joseph Paul, and Mallory Livingston. 2019. "A Review of Partnerships between Transportation Network Companies and Public Agencies in the United States."

Seed, Ian. 2017. MCDA. Lulu. com.

Shoup, Donald. 2017. The High Cost of Free Parking: Updated Edition. Routledge.

Triantaphyllou, Evangelos. 2000. "Multi-Criteria Decision Making Methods." In Multi-Criteria Decision Making Methods: A Comparative Study, 5-21. Springer.

“U.S. Census Bureau QuickFacts: West Virginia." 2019. July 1, 2019. https://www.census.gov/quickfacts/fact/table/WV/PST045219.

"USDA ERS - Urban Influence Codes." 2019. 2019. https://www.ers.usda.gov/dataproducts/urban-influence-codes.aspx.

Vafaei, Nazanin, Rita A. Ribeiro, and Luis M. Camarinha-Matos. 2018. "Selection of Normalization Technique for Weighted Average Multi-Criteria Decision Making." In Doctoral Conference on Computing, Electrical and Industrial Systems, 43-52. Springer.

Viton, Philip A. 1997. "Technical Efficiency in Multi-Mode Bus Transit: A Production Frontier Analysis." Transportation Research Part B: Methodological 31 (1): 23-39.

Vlahogianni, Eleni, Konstantinos Kepaptsoglou, and Matthew G. Karlaftis. 2015. "Analyzing Performance of Transit Lines and Depots: A Data Envelopment Analysis Approach."

Wachs, Martin. 1989. "US Transit Subsidy Policy: In Need of Reform." Science 244 (4912): 154549.

Walker, Warren E. 2000. "Policy Analysis: A Systematic Approach to Supporting Policymaking in the Public Sector." Journal of Multi-Criteria Decision Analysis 9 (1-3): 11-27.

Welch, Timothy F. 2013. "Equity in Transport: The Distribution of Transit Access and Connectivity among Affordable Housing Units." Transport Policy 30: 283-93.

$\mathrm{Xu}, \mathrm{Ze}$-Shui, and Jian Chen. 2007. "An Interactive Method for Fuzzy Multiple Attribute Group Decision Making." Information Sciences 177 (1): 248-63.

Yoon, K. 1980. "System Selection by Multiple Attribute Decision Making." Vol.” Ph. D. Thesis Manhatan, Kansas: Kansas State University.

Żak, Jacek, Yuval Hadas, and Riccardo Rossi. 2017. Advanced Concepts, Methodologies and Technologies for Transportation and Logistics. Vol. 572. Springer. 